\title{
Error propagation in time-dependent probability of occurrence for characteristic earthquakes in Italy
}

\author{
Laura Peruzza • Bruno Pace · Fabio Cavallini
}

Received: 15 December 2007 / Accepted: 28 July 2008 / Published online: 1 October 2008

(C) The Author(s) 2008. This article is published with open access at Springerlink.com

\begin{abstract}
Time-dependent models for seismic hazard and earthquake probabilities are at the leading edge of research nowadays. In the framework of a 2-year national Italian project (20052007), we have applied the Brownian passage time (BPT) renewal model to the recently released Database of Individual Seismogenic Sources (DISS) to compute earthquake probability in the period 2007-2036. Observed interevent times on faults in Italy are absolutely insufficient to characterize the recurrence time. We, therefore, derived mean recurrence intervals indirectly. To estimate the uncertainty of the results, we resorted to the theory of error propagation with respect to the main parameters: magnitude and slip rate. The main issue concerned the high variability of slip
\end{abstract}

Electronic supplementary material The online version of this article (doi:10.1007/s10950-008-9131-1) contains supplementary material, which is available to authorized users.

L. Peruzza $(\varangle) \cdot$ F. Cavallini

OGS-Istituto Nazionale di Oceanografia e Geofisica

Sperimentale, Sgonico, Trieste, Italy

e-mail: lperuzza@inogs.it

B. Pace

GEOSISLAB-Università degli Studi

"G. D'Annunzio", Chieti Scalo, Italy rate, which could hardly be reduced by exploiting geodetic constraints. We did some validation tests, and interesting considerations were derived from seismic moment budgeting on the historical earthquake catalog. In a time-dependent perspective, i.e., when the date of the last event is known, only $10-15 \%$ of the 115 sources exhibit a probability of a characteristic earthquake in the next 30 years higher than the equivalent Poissonian probabilities. If we accept the Japanese conventional choice of probability threshold greater than $3 \%$ in 30 years to define "highly probable sources," mainly intermediate earthquake faults with characteristic $\mathrm{M}<6$, having an elapsed time of $0.7-1.2$ times the recurrence interval are the most "prone" sources. The number of highly probable sources rises by increasing the aperiodicity coefficient (from 14 sources in the case of variable $\alpha$ ranging between 0.22 and 0.36 to 31 sources out of 115 in the case of an $\alpha$ value fixed at 0.7 ). On the other hand, in stationary time-independent approaches, more than two thirds of all sources are considered probabilistically prone to an impending earthquake. The performed tests show the influence of the variability of the aperiodicity factor in the BPT renewal model on the absolute probability values. However, the influence on the relative ranking of sources is small. Future developments should give priority to a more accurate determination of the date of the last seismic event for a few seismogenic sources of the DISS catalog 
and to a careful check on the applicability of a purely characteristic model.

Keywords Brownian passage time renewal model • DISS - Earthquake probability • Characteristic earthquake $\cdot$ Italy

\section{Introduction}

Time-dependent seismic hazard assessment and earthquake probabilities have been internationally recognized as "hot themes" in recent years, and scientists who are releasing academic and/or applicative results in different countries face the problem of using the best data and model available to gain reliable estimates (Cramer et al. 2000; Matthews et al. 2002; Perea and Atakan 2007; Petersen et al. 2007).

With the caution that is necessary in using statistics, we point out that Italy has experienced approximately 350 deaths per year due to earthquakes in the last millennium (see Fig. 1), a shocking number, which rises to even more than 1,000 casualties per year if we consider the twentieth century only. In Italy, the fatalities are due to moderate-to-strong events in regions inhabited

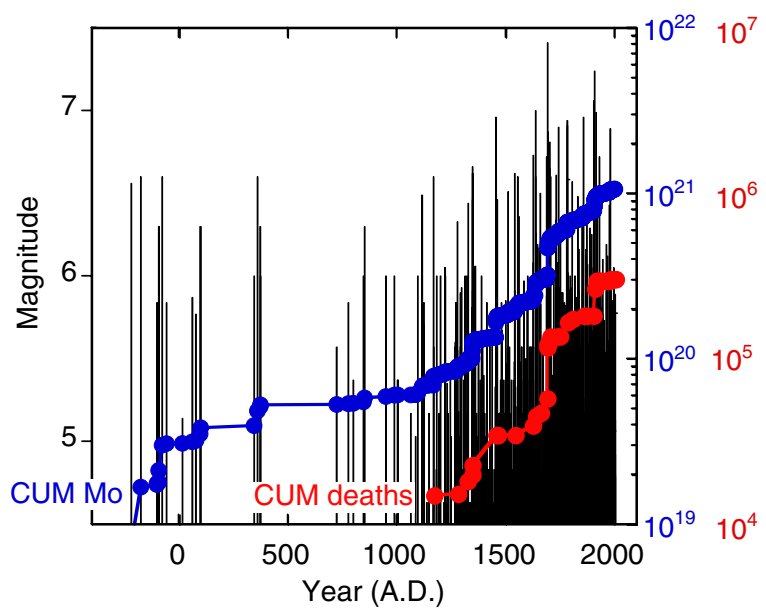

Fig. 1 Simplified representation of the Italian earthquake catalog (CPTI Working Group 2004); magnitude (black bars, left $y$-axis) is equivalent to $M_{w}$ (MAW column in the original source); cumulative seismic moment release (right $y$-axis in blue, $M_{o}$ given in newton meter) and cumulative casualties curve (right $y$-axis in red) for a long time and subjected to small deformations. Only two events in the earthquakes catalog (CPTI Working Group 2004) are referred to as $M>7$ earthquakes (but magnitudes are still controversial), the deformation rates from geodetic measurements are in the order of 20-30 nanostrain per year (e.g., Serpelloni et al. 2005) in this part of the Mediterranean, and consequently, long-term slip rates of Italian faults rarely exceed $1.5 \mathrm{~mm} /$ year. Small values, if compared with those of other seismically active regions. The high death toll in the past justifies a primary interest for Italian society to identify areas that are most "ready" for a medium-to-large earthquake in order to prioritize the allocation of resources devoted to retrofitting buildings and infrastructures. By rephrasing Heaton's words (Heaton 2007), if we are able to prevent just $5 \%$ of the deaths in Italy due to the next $M \sim 6.5$ earthquake, we will save more lives than the ones have been lost in all other earthquakes, in Italy, for many decades; mid-to-long-term time-dependent earthquake prediction is no longer an academic affair, but a socially relevant issue.

In the frame of the activities funded by the Italian National Civil Protection Department (DPC) in the last decade, some projects (Amato and Selvaggi 2004; Peruzza 1999; Slejko and Valensise 2006) have been promoted to investigate time-dependent assumptions that are critical for the seismic risk mitigation at the national scale.

This paper aims to describe the analyses we performed in the frame of the last project ("Assessing the seismogenic potential and the probability of strong earthquakes in Italy," namely, S2 Project (Slejko and Valensise 2007), http:// legacy.ingv.it/progettiSV/Progetti/Sismologici/S2/ ProgettoS2_definitivo.pdf), which focused on:

1. the utilization of the information collected for individual seismogenic sources in a national, publicly available database (DISS Working Group 2007) to quantify the probability of occurrence of a characteristic event in a midto-long-term perspective (10-30 years);

2. the exploration of the influence on the earthquake probabilities of the uncertainties in source characterization to recognize which are the most sensitive parameters; 
3. the proposal of consensus procedural schemes to constrain the uncertainties in order to obtain robust/credible probabilities of activation.

Most of the analyses and results of the S2 project presented in this paper have been described by internal reports released during the intermediate (May 2006) and final (July 2007) phases of the project (Peruzza 2006b, 2007; Slejko and Valensise 2006, 2007; Stirling et al. 2007). These scattered results and more (elaborations done after the end of the project) find in the present paper a coherent, up-to-date, and synthetic presentation.

This work is not intended to release seismic hazard mapping alternative to the one recently adopted by Italian law (Gruppo di Lavoro 2004); we hope the paper can represent a contribution in identifying consensus priority areas for seismic risk reduction purposes.

\section{Individual seismogenic sources and characteristic earthquake in Italy}

The individual seismogenic sources used in this analysis are those gathered in the Italian database compiled by Istituto Nazionale di Geofisica e Vulcanologia (INGV) researchers (DISS Working Group 2007). In the first public version of the database (Version 2, Valensise and Pantosti 2001), the individual seismogenic sources were addressed as geological sources (GG) to keep them distinct from other potential sources (macroseismic sources [MS]), which lack clear geological signatures and are defined by means of seismological evidence only. The "basic assumption that each seismogenic source tends to generate repeatedly and exclusively its largest allowed earthquake, that is the assumption of "characteristic" behaviour (in the sense of Schwartz and Coppersmith 1984) for what concerns fault location, geometry and size" (Valensise and Pantosti 2001) holds for the GG, and for the MS sources too. Database of Individual Seismogenic Sources (DISS) Version 3 introduced a new rank of sources, namely, seismogenic areas (SA), which are conceived by schematizing geologic regional trends, and should collect macroseismic sources and several individual sources, known or unknown. In a first approximation, SAs behave according to a Gutenberg-Richter $(\mathrm{G}-\mathrm{R})$ frequency distribution.

The scientific community is equally divided about the implementation priorities of timedependent probability models (see, for example, the Straw Poll Results in Workshop 7 at http:// www.wgcep.org); characteristic earthquakes, seismic gaps, and quasiperiodicity models are alternative views to those statistical studies (e.g., Kagan and Jackson 1991, 1999; Faenza et al. 2003 for Italy), suggesting earthquake clustering in space and time. In these last studies, long-term forecasts are essentially an empirical description of observed spatial clustering; the temporal clustering is based on some completeness assumptions of having a record of observed events sufficient for statistical purposes. An appealing issue that can solve these conflicting views is the temporal clustering of "characteristic earthquake" individual sources; different research teams are working on it with promising results (e.g., Casarotti and Piersanti 2005; Marzocchi et al. 2006; Zoller et al. 2007, and the S2 results of the Research Unit 4.3 at http://legacy.ingv.it/progettiSV/Progetti/Sismo logici/S2/Task_4.pdf and http://legacy.ingv.it/ progettiSV/Progetti/Sismologici/S2/Deliverables/ S2_Deliverables_4.2.1.htm). By now, we simply accept the assumptions adopted by the DISS compilers.

We limit our analyses to the individual geological sources because they alone have independent observations to legitimate the long-term seismic behavior: structural-geological data, paleoseismic observations, and historical and/or instrumental earthquakes associated to the faults. In addition, individual sources represent the causative sources for more than $85 \%$ of the fatalities graphed in Fig. 1, and about one sixth of the large, active faults have not clearly expressed their seismic potential during historical times. Figure 2 represents the distribution of maximum, characteristic magnitudes of individual sources in the different DISS versions released since the year 2001. Note the increase of sources associated to a geological signature in the last few years and the progressive 

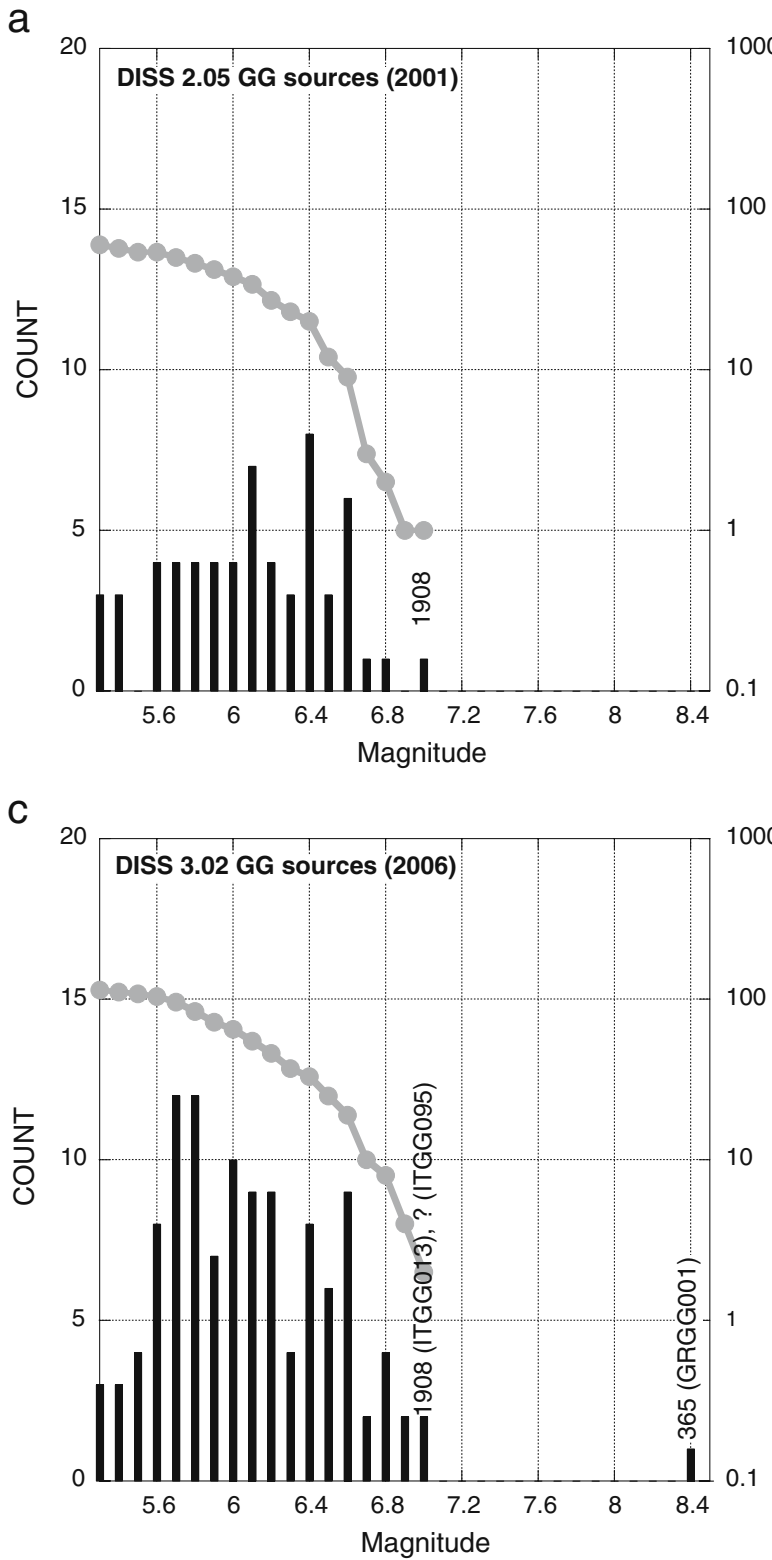

Fig. 2 Histograms of the maximum magnitude of GG seismogenic sources in DISS (DISS Working Group 2007): a sources of DISS 2.05 (Valensise and Pantosti 2001); b DISS 3.0 (2005, beginning of the S2 project); c DISS 3.02 (released in September 2006, reference fault model chosen by the S2 project); d DISS 3.04 (released after the

change in magnitude distribution; nearly all the DISS releases depart from a linear-log G-R behavior, approximately for magnitude smaller than 6.4. The DISS version 3.02, released in September 2006 , has been selected as reference fault model in b
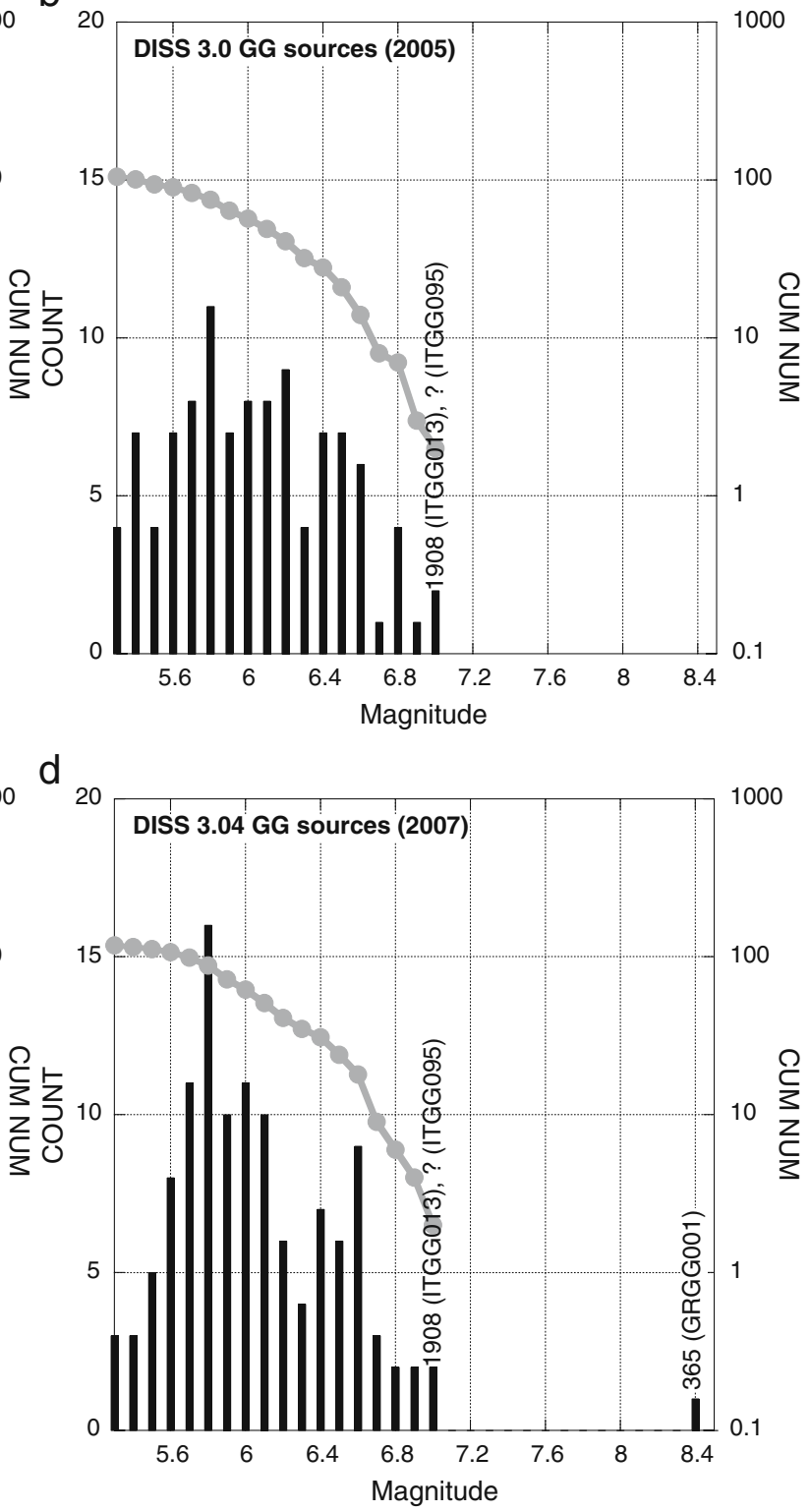

end of the S2 project, October 2007). Left $y$-axis represent the number of sources in 0.1 magnitude bin (black bars), right $y$-axis the cumulative number of sources (curve in gray): departure from linear-log trend of $\mathrm{G}-\mathrm{R}$ relationships is approximately for $M<6.4$

the frame of the S2 project (see this issue and the final S2 report at http://legacy.ingv.it/progettiSV/ Progetti/Sismologici/S2.htm) to represent a common basis for the elaborations performed with different techniques by all the research groups. 
It contains 115 individual sources where the last earthquake rupture is known for 99 faults. A summary table of geological sources is given in the Electronic Supplementary Materials (ESM 1).

By comparing similar-sized countries, the 2002 California seismic hazard model (see Jordan et al. 2006 and references therein) incorporates nearly 200 fault sources, generating thousands of earthquake ruptures, divided into two classes: Atype faults have high slip rate (generally greater than $5 \mathrm{~mm}$ /year), paleoseismic data that constrain the recurrence intervals of large earthquakes, and $100 \%$ of the total seismic energy release is taken by a characteristic model; B-type faults have slip rates and fault locations whose published values can be used to estimate a recurrence interval, but the total seismic energy release is partitioned between the characteristic and truncated G-R magnitude-frequency distributions (usually two thirds and one third, respectively).

The individual geological sources of the DISS database are comparable with the B-type in terms of available information, slip rates, and recurrence intervals, but they are treated like A-type faults with iterative full-fault ruptures.

\section{Earthquake probabilities: recipes and ingredients}

Earthquake probabilities for a specified time span for each rupture in a given fault model constitute what is internationally referred to as earthquake rupture forecast (ERF, see Field et al. 2003 and references therein). A description of the main concepts, models, and algorithms used in estimating the probability of a major event on Italian geological sources is given below, together with the recipes adopted to overcome lack of available information.

\subsection{Probabilistic model}

Many probability models have been proposed in literature to forecast the recurrence of a rupture source (see, for example, the introduction in Abaimov et al. 2007 and references therein).

The Brownian passage time (BPT) renewal model based on the occurrence time of last event is here used and compared with a Poisson model, which is suitable when time-dependent issues are not applicable.

The probability density function of the BPT distribution of recurrence time $t$ is given by Matthews et al. (2002):

$P(t)=\sqrt{\frac{\mu}{2 \pi \alpha^{2} t^{3}}} e^{-\frac{(t-\mu)^{2}}{2 \mu \alpha^{2} t}}$

where $\mu$ is the mean recurrence time and $\alpha$ is the coefficient of variation (aperiodicity) of the distribution, given by the ratio $\alpha=\sigma / \mu$ of the standard deviation $\sigma$ over the mean $\mu$.

In commercial and open-source software, distribution 1 is frequently referred to as the inverse Gaussian distribution and is equivalently written as:

$P(t)=\sqrt{\frac{\lambda}{2 \pi t^{3}}} e^{-\lambda \frac{(t-\mu)^{2}}{2 \mu^{2} t}}$

where $\lambda=\mu / \alpha^{2}$ is a scaling parameter.

The BPT distribution has a flexible shape covered by varying $\alpha$; small aperiodicity values correspond to nearly symmetrical densities with pronounced central tendency near the mean value; increasing the $\alpha$ 's, we obtain distributions similar to log-normal, skewed to the right, and peaked at a smaller value than the mean. The hazard function (instantaneous failure rate, given by the ratio $\mathrm{PDF} /(1-\mathrm{CDF}))$ is null at $t=0$, reaches a maximum at some finite time greater than the density's mode:

$\frac{-3 \mu^{2}+\mu \sqrt{4 \lambda^{2}+9 \mu^{2}}}{2 \lambda}$,

and then decreases asymptotically toward the finite value $\lambda / 2 \mu^{2}$, not to zero like the log-normal model. This behavior is of peculiar interest when modeling earthquakes in a physically consistent way (see the details in Matthews et al. 2002). A simple representation of BPTs is given in Fig. 3. Note the progressive shift of the peaks in PDF distribution, as far as $\alpha$ values increase $(0.1,0.25$, $0.5,1)$; the given $\mu=0.5$ is taken with respect to an arbitrary time unit $T$ (e.g., $T=1,000$ years). A notebook for interactive representation of the most commonly used distribution functions in earthquake source modeling, for Mathematica ${ }^{\circledR}$ users only, is given in the ESM 2. 

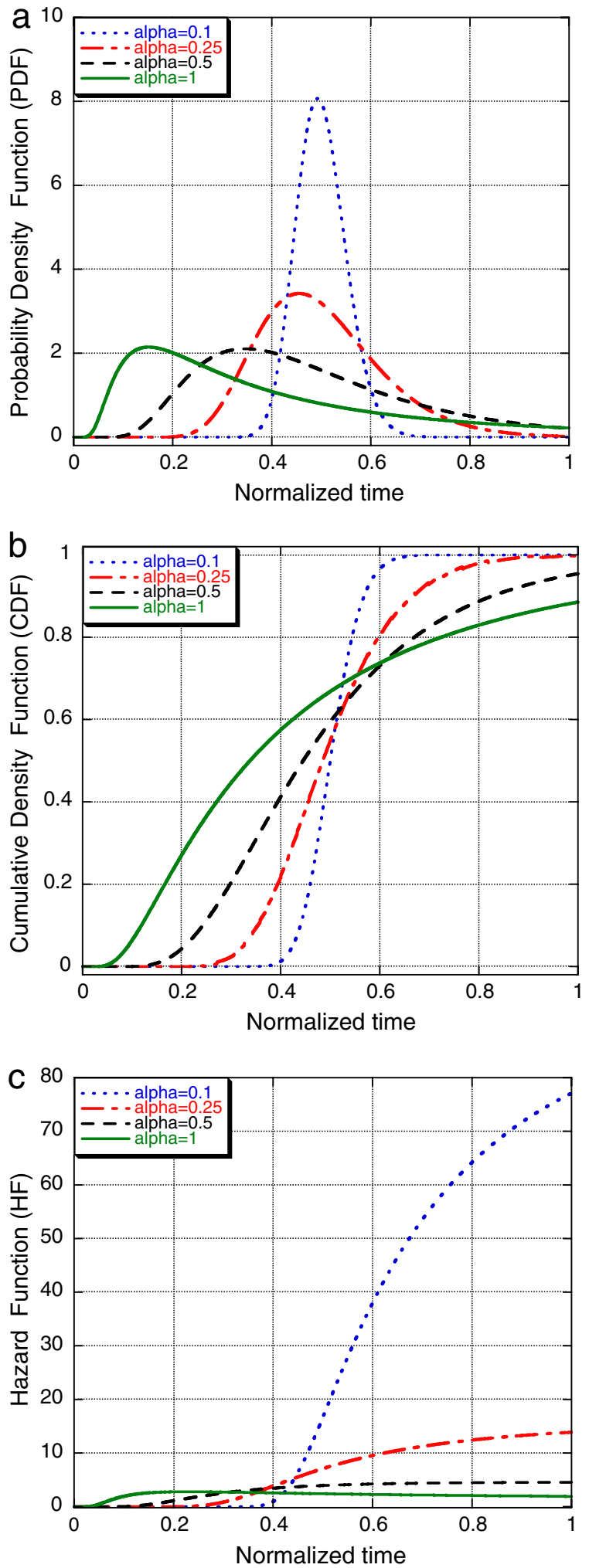

Fig. 3 BPT distribution model for assigned $\mu$ and $\alpha$ parameters. In all frames, the mean time is $\mu=0.5 T$ where $T$ is an arbitrary time unit (say, $T=1,000$ years) used for the horizontal axis also. Nondimensional values $\alpha=0.1$, $0.25,0.5$, and 1 correspond to dotted, dash-dotted, dashed, and continuous lines, respectively. a Probability density function; $\mathbf{b}$ cumulative density function; $\mathbf{c}$ hazard function

In the BPT model, the standard deviation $\sigma$ (and then, in turn, the coefficient of variation $\alpha)$ describes an aleatory behavior in a series of recurrence intervals. The fluctuations due to the natural phenomena are not related to the epistemic uncertainty of the mean recurrence time. In our opinion, this is true only in theory. Worldwide practice (e.g., see Ellsworth et al. 1999 for California; Shimazaki 2006 for Japan; Pantosti et al. 2008 for Turkey) derives $\alpha$ values from observed sets of interoccurrence times, which are affected by epistemic errors due, at least, to completeness and sensitivity reasons (possible missed events and uncertainties in paleoseismic event dates). The aperiodicity $\alpha$ associated to a fault, or to a group of characteristic earthquake sources, should be, therefore, considered a representative of both the aleatory and epistemic variability.

Formally, if we accept that intertimes due to the physical properties of the fault are represented by a random variable $\tau_{\text {ale }}$ with mean $\mu_{\text {ale }}$ and standard deviation $\sigma_{\text {ale }}$, independent from the intertimes due to epistemic uncertainty $\tau_{\text {epi }}$ with $\mu_{\text {epi }}$ and $\sigma_{\text {epi }}$, the global aperiodicity factor is:

$\alpha=\sqrt{\frac{\alpha_{\mathrm{ale}}^{2}}{\left(1+\frac{\mu_{\mathrm{epi}}}{\mu_{\mathrm{ale}}}\right)^{2}}+\frac{\alpha_{\mathrm{epi}}^{2}}{\left(1+\frac{\mu_{\mathrm{ale}}}{\mu_{\mathrm{epi}}}\right)^{2}}}$,

and noteworthy, if $\mu_{\text {ale }} \ll \mu_{\text {epi }}$, then $\alpha \cong \alpha_{\text {epi }}$. Unfortunately, we cannot split the two components, and $\alpha$ 's are usually given by preset values.

\subsection{Recurrence time}

Mean recurrence time $\left(T_{\text {mean }}\right)$ and its variability $\left(\sigma_{T \text { mean }}\right)$ are the basic ingredients to compute earthquake probability, both under Poissonian assumptions (where $\sigma=T$ ) and in time-dependent approaches (where the sample mean and standard deviation enter in the chosen probabilistic model). 
Even if the term "mean recurrence time" is often ambiguously used to address different things (intertimes, inverse of frequency of occurrence), here with "recurrence time" we refer to the recurrence intervals-or interevent time-between similar-sized, maximum expected earthquakes on the individual source.

The ideal situation for a given fault segment is to have a long list of associated events, so that mean and variability derive directly from observations. The actual observations of multiple, characteristic events on the same fault segment in Italy are definitely few, mostly represented by recent active sources in Central Italy. Therefore, the value of $T_{\text {mean }}$ has to be derived by the combination of fault rupture parameters. The simple ratio:

$T=\frac{S_{E}}{V}$

where $S_{E}$ is slip-per-event and $V$ the slip rate of a fault segment may be used for such a purpose. Another widely used practice invokes the criterion of "segment seismic moment conservation" proposed by Field et al. (1999):

$T=\frac{1}{\text { Char_Rate }}=\frac{10^{(1.5 M+9.05)}}{\mu V L W}$

where $T$ is the mean recurrence time in years, Char_Rate is the annual mean rate of occurrence, $M$ is the magnitude, $\mu$ is the shear modulus in newton per square meter, $V$ is the long-term slip rate in meter per year, and $L$ and $W$ are the geometrical parameters of the fault in meter. The coefficients 1.5 and 9.05 in Eq. 4 are those proposed by Hanks and Kanamori (1979) in the relationship to derive the seismic moment (in newton meter) from magnitude; formally they refer to $M_{\mathrm{s}}$, but we can assume they are equivalent to $M_{\mathrm{w}}$ for the way magnitudes have been assigned in DISS and for the magnitude range of interest.

In previous papers, we presented some proxy approaches to recurrence times applied to regionally based and state-wide Italian source databases (Pace et al. 2006; Peruzza 2006a; Peruzza et al. 2007 and references therein).

Here, we firstly present the results obtained with similar techniques on the S2 reference fault model (DISS 3.02) with respect to the values as- signed by the database compilers (RecIntMin and RecIntMax given in DISS); then, we will introduce formal error propagation in recurrence time computations.

Some sensitivity tests proposed at the end of the first year of the S2 project (Peruzza 2006b) suggested to investigate separately the variability in recurrence times of individual geologic sources due to the size (magnitude) of the characteristic event with respect to the component related to the deformation process (slip rate on the fault). We will demonstrate that, without a formal treatment based on error propagation, the uncertainties on the deformation velocity blur the feasibility of time-dependent approaches. Now a description of the two basic parameters follows.

\subsubsection{Magnitude}

Magnitude in DISS (MaxMag) is a sharp value given by an expert judgement based on the available information. As illustrated in Fig. 4a, the most represented case is the magnitude value adopted from macroseismic data points $(34 \%)$ or records of historical earthquake catalog $(21 \%)$; about $20 \%$ of the magnitude assignments derive
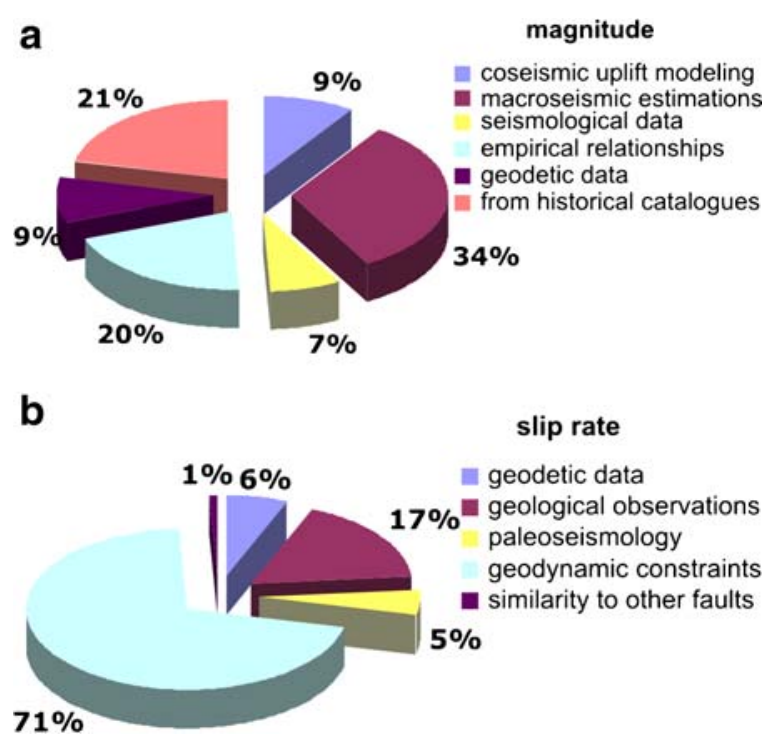

Fig. 4 Pie histograms of the methods used in assigning parameters to the GG sources in DISS 3.02 (released in September 2006 and used for the final results of the S2 project): a concerning magnitude; $\mathbf{b}$ concerning slip rate 
directly from empirical relationships. The uncertainty associated to magnitude is not explicitly given, but a quality indicator on magnitude, ranging from 1 to 3 , is given.

The use of magnitude/rupture size relationships is common in international literature and, despite the huge amount of data released in the last decade, the empirical relationships proposed by Wells and Coppersmith (1994) are still the most widely used. In the frame of the Working Group for Californian Earthquake Probability (WGCEP, http://www.wgcep.org), a specific activity (task 7) is engaged in reviewing possible alternative relationships, but the preliminary recommendations drawn during the WGCEP Meeting \#10 Report are scarcely applicable to Italy because the size and dominant mechanisms considered in that report are those of interest in California. We, therefore, decided to check the original magnitude MaxMag given in DISS by applying the original empirical relationships proposed by Wells and Coppersmith (1994). According to the style of the fault, $M_{1}$ is the mean value of magnitude obtained by applying the relationships based on subsurface length, $M_{2}$ by using the rupture area $(L \times W)$.

An additional magnitude value is given by the application of the relationship that links the magnitude $\left(M_{3}\right)$ to the scalar value of seismic moment ( $M_{0}=\mu D L W=\mu k L^{2} W$ where $\mu$ is the rigidity modulus and $k$ is the strain drop, defined as the displacement to length ratio $D / L$ ), accepting the reasonable assumption that strain drop is constant $^{1}$ in a homogeneous seismotectonic region (Scholz and Cowie 1990). In particular, for the intraplate region of Italy, we used the value $k=$ $3 \times 10^{-5}$ from Selvaggi (1998). Moreover, a control on magnitude values was done using the aspect ratio relationships $(M \%)$ derived on a Wells and Coppersmiths's dataset, slightly modified (Peruzza and Pace 2002). Figure 5a represents the magnitudes given in DISS 3.02 (MaxMag)

\footnotetext{
${ }^{1}$ The variation of a factor of 10 in strain drop (but the same is valid for the shear modulus as well) implies a change in $M_{3}$ of approximately 0.65 ; by doubling the strain drop from 3 to $6 \times 10^{-5}$ (values from stress drop computed in the Colfiorito area by Capuano et al. (2000)) the variability is approximately 0.1 . We will introduce these uncertainties in the estimates obtained via error propagation.
}

and those computed using the geometrical parameters; sources are sorted by decreasing latitude and increasing longitude (latitude of three reference Italian cities marked by the labels, full list of sources in ESM 1). Simple statistics on the graphed values (Fig. 5b) suggest the general comment that the expert judgment is slightly more cautious than the mean magnitude value obtained from the rupture size; excluding the source located in Greece (GRGG001, last source shown in the graphs, kept for homogeneity reasons although it lies out of the maps presented hereinafter), only five sources have differences above 0.1 [ITGG100 Bagnacavallo (0.12), ITGG035 Rimini (0.13), ITGG024 Mondolfo (0.32), ITGG053 Ripabottoni (0.10), ITGG014 Belice (0.26)]. The dispersion on the computed values (Fig. 5c) is underestimated at this stage, as no standard error is taken into account when using empirical regression relationships; nevertheless, it shows a trend in latitude that can somehow reflect the difficulties in understanding the faults segmentation process and, therefore, the parameterization of the maximum fault rupture in dominant compressive regimes (Alps, Northern Apennines).

\subsubsection{Slip rate}

The deformation model, i.e., the long-term slip rate for known major faults and/or moment accumulation rates throughout a region, is by far the most critical ingredient in defining the earthquake occurrence. The slip rate data stored in DISS (SlipRateMin, SlipRateMax) for geological sources are based on expert judgment and mostly on the extrapolation from adjacent/similar context faults. As shown in Fig. 4b, about two thirds of the sources have the slip rate values assumed from geodynamic constraints and not directly calculated from geologic data or paleoseismic observations. Most of the faults, therefore, exhibit the same hypothesized values given by the interval of $0.1-1 \mathrm{~mm} /$ year; this variability in the deformation velocities implies a factor of 10 in recurrence times. As slip rate is highly speculative, DISS does not assign aseismic slip factors to the fault, and then we have used the long-term slip rate as fully representative of the expected seismicity rates. 


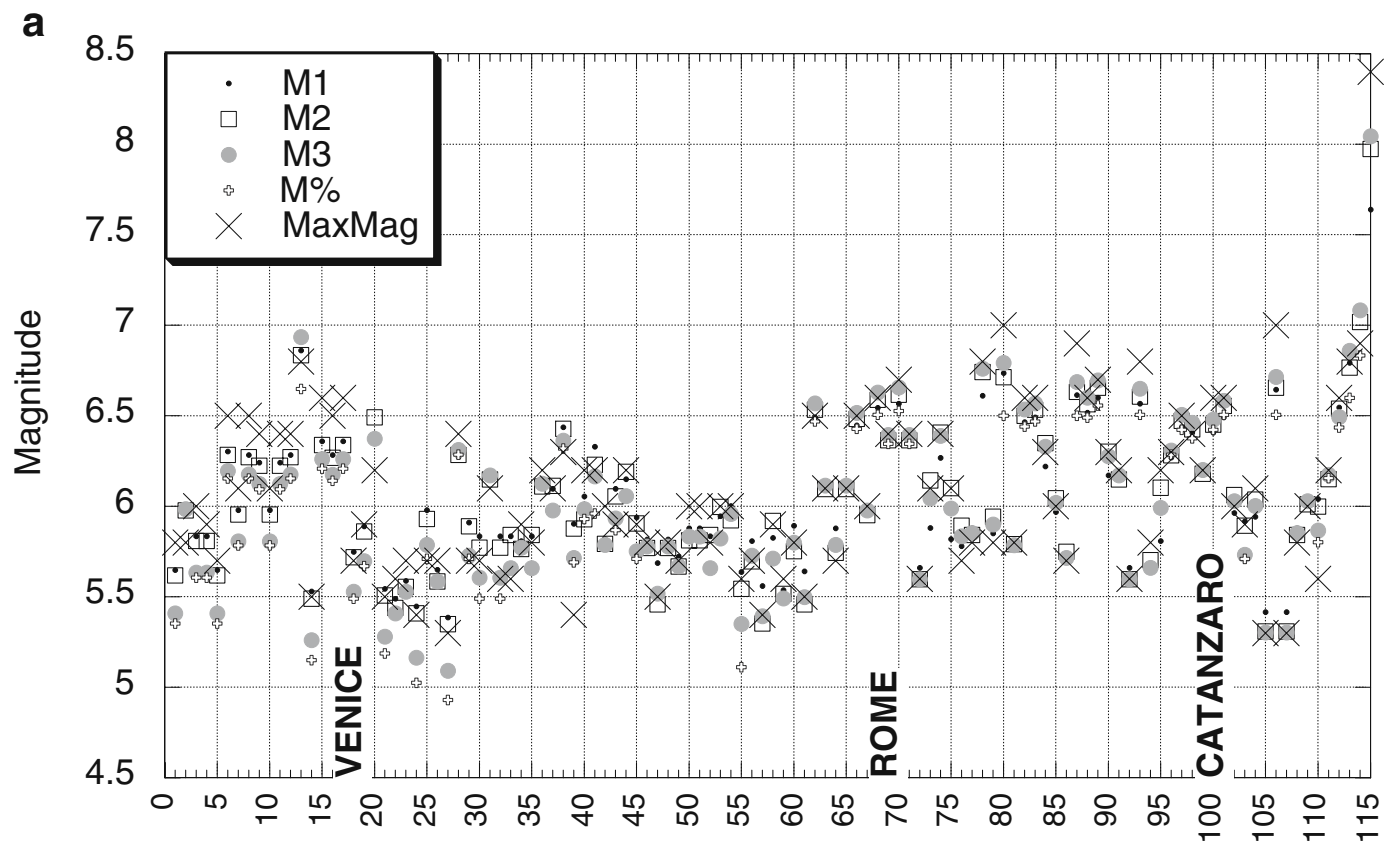

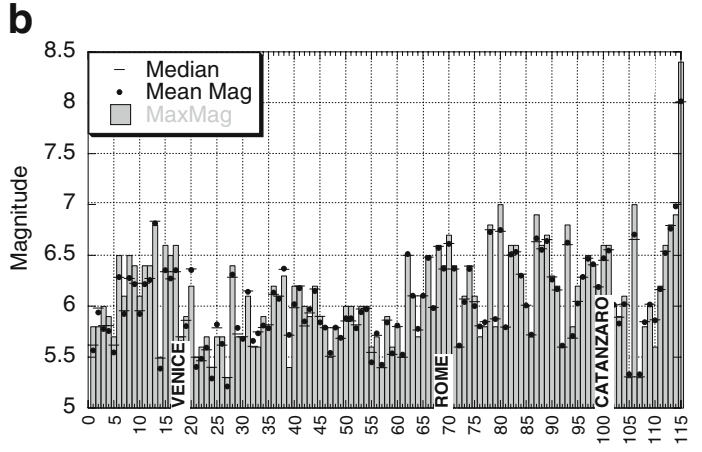

Fig. 5 Magnitudes for DISS 3.02 GG sources: a computed from geometric parameter and given in the database (see the text); b comparison of MaxMag given in DISS with the mean and median values; $\mathbf{c}$ standard deviation on the

We did some tests to lower the uncertainties in the long-term slip rates using geodetic constraints. A preliminary set of geodetic data became available for the purposes of the project in July 2006 (namely, activities done in the frame of task 3, see at http://legacy.ingv.it/progettiSV/Progetti/ Sismologici/Relazioni_I_fase/Rendicontazione_I_ fase_S2.pdf).

Since then, we tried to apply the strain rate values directly to the faults to reduce the range of expected slip rate. The recipe is based on simple rules. We recall that the strain rate is the variation of strain in time and that the seismic strain is the

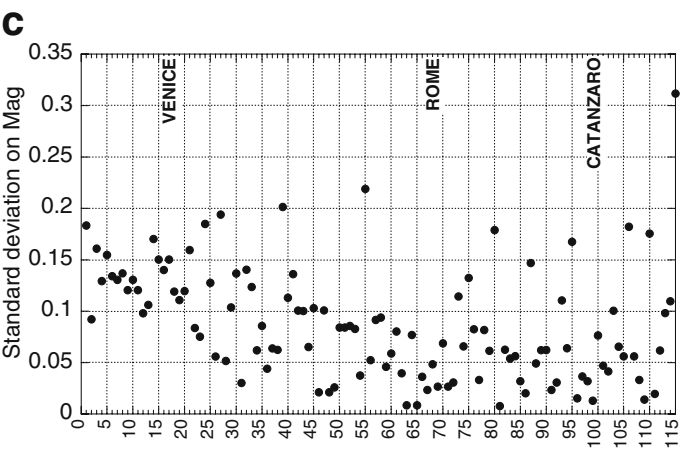

computed magnitudes. Sources are sorted according to decreasing latitude and increasing longitude (source numbered in the full list of ESM 1)

displacement over an effective length; moreover, we assume that this effective length $L^{*}$ is approximately equal either to the square root of the rupture area $A=L \times W$ (for normal or reverse faults) or to the total length $L$ of the fault (for strike slip faults). Therefore, we have:

$$
\begin{aligned}
& L_{\text {normal } / \text { reverse }}^{*} \approx \sqrt{A}=\sqrt{L W} ; \quad \dot{e}=\frac{1}{l} \frac{\mathrm{d} l}{\mathrm{~d} t}=\frac{v}{l} ; \\
& L_{\text {strikeslip }}^{*} \approx L \\
& \Delta \varepsilon=\frac{D}{L^{*}}
\end{aligned}
$$


where $\dot{e}$ is the geodetic strain rate, $v$ is the velocity, $\Delta \varepsilon$ is the seismic strain on a fault, and $D$ is the displacement. Accordingly, the first rough boundary condition from geodesy to slip rate values on the fault is:

$V_{\text {horizontal }}=\dot{e} \times L^{*}$

and can be resolved along the fault plane using trigonometry.

These simple rules are implicitly based on crude assumptions as: (a) no matter how the area to compute the strain rate from some velocity points is shaped, the strain rate is a property that equally belongs to all the points of that area (which is physically unacceptable, but unsolvable using sparse GPS stations); (b) all the strain is transformed into seismic energy (which is not reasonable), defining an upper limit to slip rate, and possibly overestimates the seismic activity; (c) the short-term deformation of geodetic observation is representative of the long-term behavior of the fault (which is a controversial issue). This methodological approach has been applied to several strain rate elaborations, released during the project, which used GPS observations and numerical modeling. Some promising results have been obtained using the values of 27-47 Nstrain given in 2006 by Braitenberg (see first year report and Gabrieli et al. 2006 for the Friuli areaNE Italy). But apart from this special case, all the other elaborations (Barba and Caporali, personal communication) lead to very low slip rates assigned to the faults, often smaller than the minimum values given in DISS. Figure 6 summarizes two tests done in 2006 and 2007 for GG sources in NE Italy. This simple recipe remains controversial, and results are hardly credible; for these reasons, the final earthquake probabilities do not include geodetic constraints in the computation. More advanced deformation models, accounting for GPS-derived strain rate observations or modeling, should be used and tested in future researches.

\subsubsection{Proxy recurrence times}

In the 2 years of the $\mathrm{S} 2$ project, we released different estimates of mean recurrence time (and its variability) of the individual seismogenic sources;

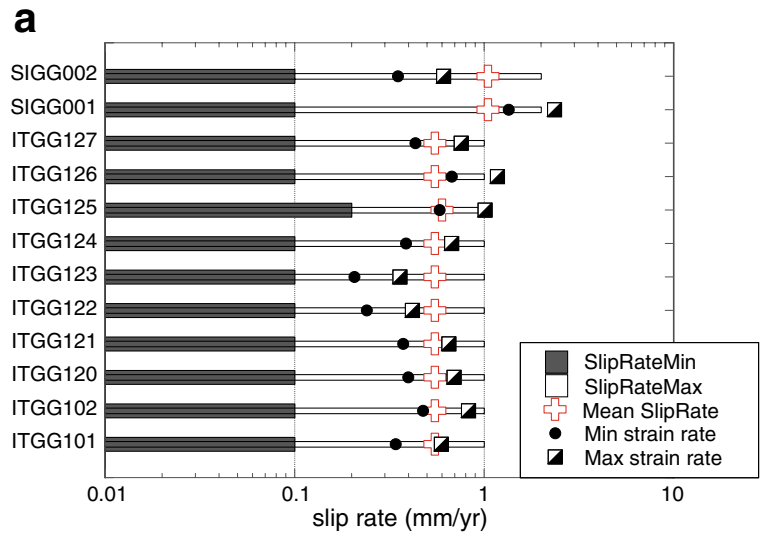

b

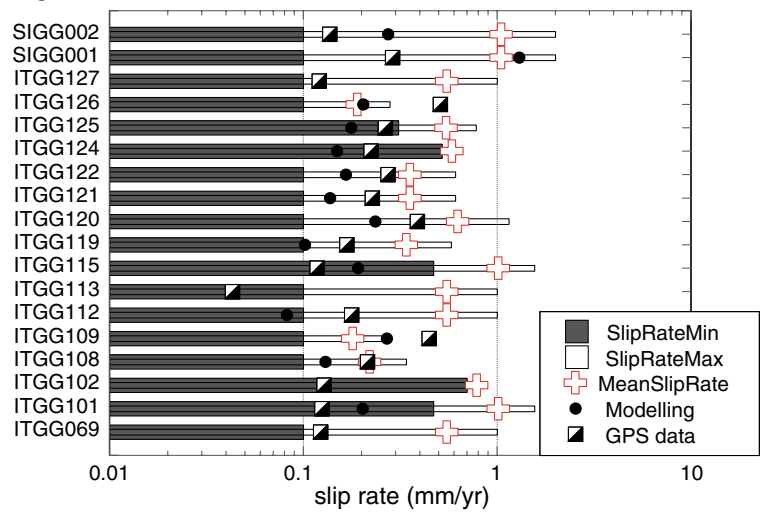

Fig. 6 Comparison of slip rates for GG sources in NE Italy. a Elaboration done in 2006: values given in the database DISS 3.0 (horizontal bars), mean values used in "mag (2006)" results (red crosses), slip rates derived via strain rate using Braitenberg regional results of 27-47 Nstrain assigned to the whole area (dots and squares, see also Fig. 12 and the text). b Elaboration done in 2007: referring to DISS 3.02 (horizontal bars), mean values used in "Spring (2007)" results (red crosses), dots and squares as in a but using GPS or modeled strain rates assigned to seismogenic areas by Barba and Caporali (personal communication, March 2007)

they reflect conceptual evolutions in data treatment, and changes in the fault model too.

In the intermediate results (end of the first year, Peruzza 2006b, obtained by applying to the initial fault model DISS 3.0 techniques similar to the ones proposed in the past-see details in Pace et al. 2006; Peruzza 2006a), we subdivided the variability in characterizing the individual geologic sources into two main components, one pertaining the expected magnitude of the characteristic event, and the other one related to the 
deformation model (slip rate on the fault). The same processing applied to the DISS 3.02 fault model is hereinafter commented and referred to as spring 2007 results (Peruzza 2007). Concerning the magnitude variability, we demonstrated that: (1) the uncertainties introduced by the proxy on magnitudes are small, comparable, or smaller than the experimental data errors (see Fig. 5); (2) the recurrence times derived by using variable magnitudes $\left(M_{1}, M_{2}, M_{3}, M \%\right)$ but a fixed slip rate
$[$ mean $V=($ SlipMax - SlipMin $) / 2]$ usually span less than a factor of 10 , and their statistical central moment is near to the minimum recurrence time (RecIntMin) given by the fault model (see Fig. 7 and Table 1); (3) the variation coefficient ( $\alpha$ value for BPT model, given by the standard deviation over mean recurrence time) is scattered, but usually below 0.5 , and compatible with periodic or quasiperiodic processes. Conversely, with fixed magnitude (MaxMag) but full variation of the
Fig. 7 Recurrence times for DISS $3.02 \mathrm{GG}$ sources-spring 2007 results: a computed from geometric parameter and given in the database (see the text); $\mathbf{b}$ comparison of mean recurrence intervals (right axis) and aperiodicity values (left axis, $\alpha=\sigma / \mu)$ by considering separately the variability in magnitude or in slip rate: Elapsed is the time elapsed since the last event, if given.

Sources are sorted according to decreasing latitude and increasing longitude (source numbered in the full list of ESM 1)
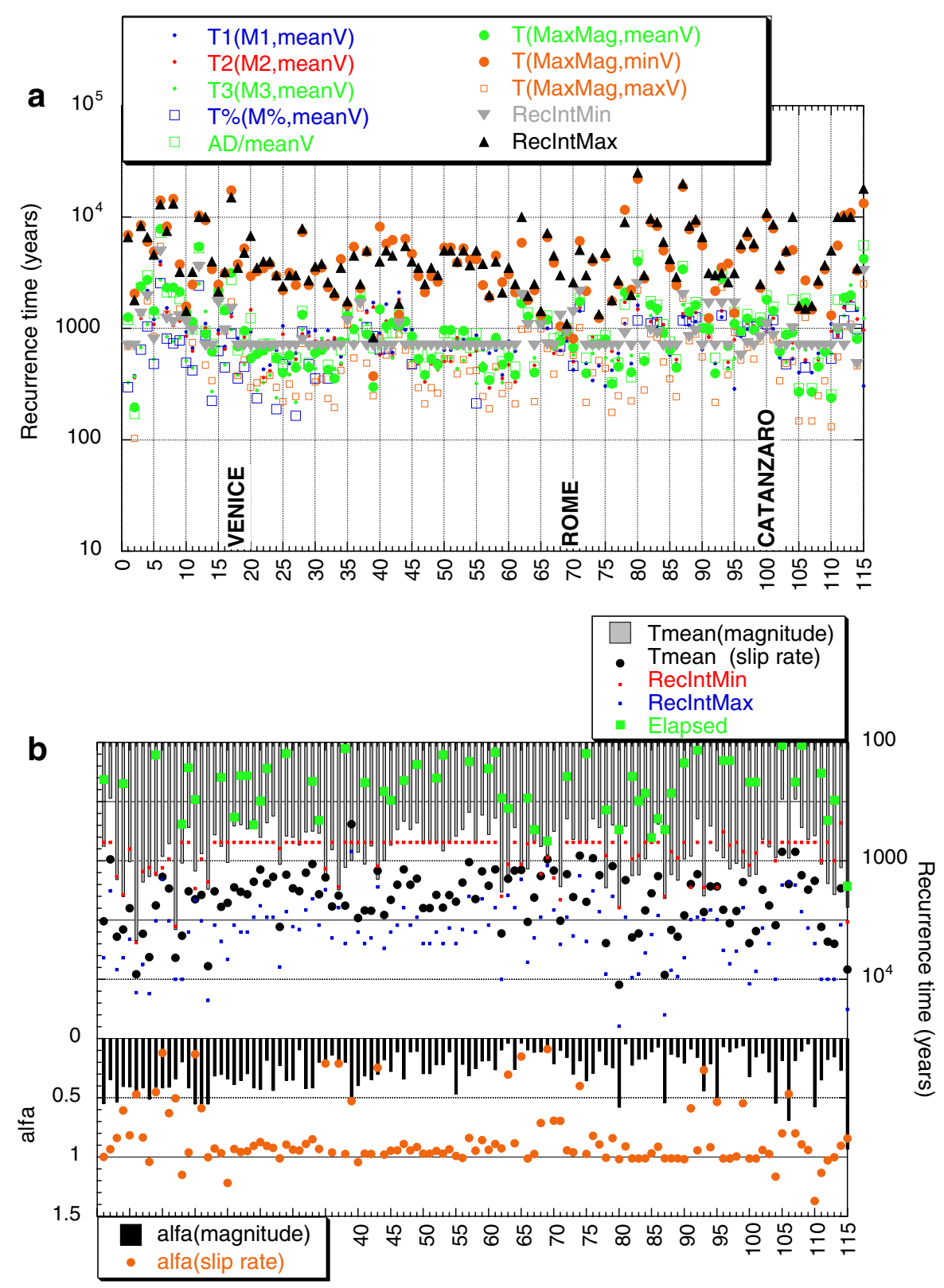
Table 1 Statistical parameter of the given recurrence interval for the $115 \mathrm{GG}$ sources in DISS 3.02 (RecIntMin, RecIntMax) and computed in this study; spring 2007 results refer to an internal report (Peruzza 2007) released for project purposes, summer 2007 are the final results including error propagation

\begin{tabular}{lccccc}
\hline & $\begin{array}{c}\text { RecIntMin } \\
\text { DISS 3.02 }\end{array}$ & $\begin{array}{c}\text { RecIntMax } \\
\text { DISS 3.02 }\end{array}$ & $\begin{array}{l}\text { Recurrence interval } \\
\text { (magnitude) spring 2007 }\end{array}$ & $\begin{array}{l}\text { Recurrence interval } \\
\text { (slip_rate) spring 2007 }\end{array}$ & $\begin{array}{l}\text { Recurrence interval } \\
\text { (error_prop.) summer 2007 }\end{array}$ \\
\hline Minimum & 480 & 833 & 295.99 & 538.92 & 250.73 \\
Maximum & 4,915 & 25,000 & $4,689.1$ & 12,938 & $3,266.8$ \\
Mean & 972.94 & $5,131.9$ & 976.53 & $2,913.6$ & 818.87 \\
Median & 700 & 3,800 & 756.44 & $2,196.8$ & 650.54 \\
Standard deviation & 620.11 & $3,912.3$ & 638.71 & $2,098.1$ & 508.32 \\
Standard error & 57.826 & 364.83 & 59.56 & 195.65 & 47.401 \\
Skewness & 3.6949 & 2.2867 & 2.8021 & 2.262 & 2.0741 \\
Kurtosis & 16.641 & 6.8235 & 11.489 & 6.0065 & 6.109 \\
\hline
\end{tabular}

deformation model (right side symbols in legend of Fig. 7a), the range of slip rate assigned to the faults causes longer recurrence times with a distinct central moment (mean recurrence time nearest to RecIntMax, Table 1); the higher variation coefficient (aperiodicity factor $\alpha$ tends to 1 for all but the best known fault) is compatible with Poisson more than quasiperiodic processes (Fig. 7b).

We, therefore, focus our attention on the formal treatment of errors to check if the uncertainties can be taken into account without loosing the confidence in a time-dependent renewal approach.

\subsubsection{Plat du jour: error propagation}

Formal error propagation may be introduced in the recurrence time calculation: the very last phase of our S2 project's analyses has been dedicated to this innovative part. The general formulation of error propagation given by a Taylor's series:

$$
\begin{aligned}
F(x, y, z, \ldots) \approx & F(\bar{x}, \bar{y}, \bar{z}, \ldots)+\frac{\partial F}{\partial x}(x-\bar{x}) \\
& +\frac{\partial F}{\partial y}(y-\bar{y})+\frac{\partial F}{\partial z}(z-\bar{z})+\ldots
\end{aligned}
$$

with variance given by:

$$
\sigma_{F}^{2} \approx\left(\frac{\partial F}{\partial x}\right)^{2} \sigma_{x}^{2}+\left(\frac{\partial F}{\partial y}\right)^{2} \sigma_{y}^{2}+\left(\frac{\partial F}{\partial z}\right)^{2} \sigma_{z}^{2}+\ldots
$$

is applied to the indirect recurrence time obtained from Eq. 4, by using partial derivatives on slip rate $V$ and magnitude $M$. Namely, the recurrence time $T_{\text {ep }}$ becomes:

$$
\begin{aligned}
T_{\mathrm{ep}} \approx & \frac{10^{(a+b M)}}{\mu V L W}-\frac{10^{(a+b M)}}{\mu V^{2} L W} \mathrm{~d} V \\
& +\frac{10^{(a+b M)} b \log (10)}{\mu V L W} \mathrm{~d} M
\end{aligned}
$$

and the corresponding error is:

$$
\begin{aligned}
\sigma_{T_{\mathrm{ep}}}^{2} \approx & \left(-\frac{10^{(a+b M)}}{\mu V^{2} L W}\right)^{2} d V^{2} \\
& +\left(\frac{10^{(a+b M)} b \log (10)}{\mu V L W}\right)^{2} d M^{2}
\end{aligned}
$$

where $\mathrm{d} M$ and $\mathrm{d} V$ are generic small variations in magnitude and slip rate, which are here substituted with the standard deviation $\sigma_{M}$ and $\sigma_{V}$ for the analysis of error propagation.

The mean value of slip rate given by DISS compilers $[V=($ SlipMax - SlipMin $) / 2]$ enters in Eqs. 9 and 10 with a standard deviation $\sigma_{V}$ given by one third of the total variation. About magnitude, we keep the five separate magnitude estimates as presented in Fig. 5; they correspond to: (i) magnitude given by subsurface rupture length $\left[M_{1}=f(L)\right]$ derived from Wells and Coppersmith (1994) relationships with the pertaining standard error ( $\sigma_{M}=0.24-0.31$ depending on focal mechanisms); (ii) the same as (i), but using the rupture area $\left[M_{2}=f(L \times W) ; \sigma_{M}=\right.$ 0.23-0.25]; (iii) magnitude from seismic moment 
Fig. 8 Recurrence times (in years) for DISS 3.02 GG sources using error propagation (in the text referred as summer 2007 results). Sources are sorted according to decreasing latitude and increasing longitude (source numbered in the full list of ESM 1).

Fictitious elapsed time of 9,999 years is graphed for the sources lacking the date of the last event

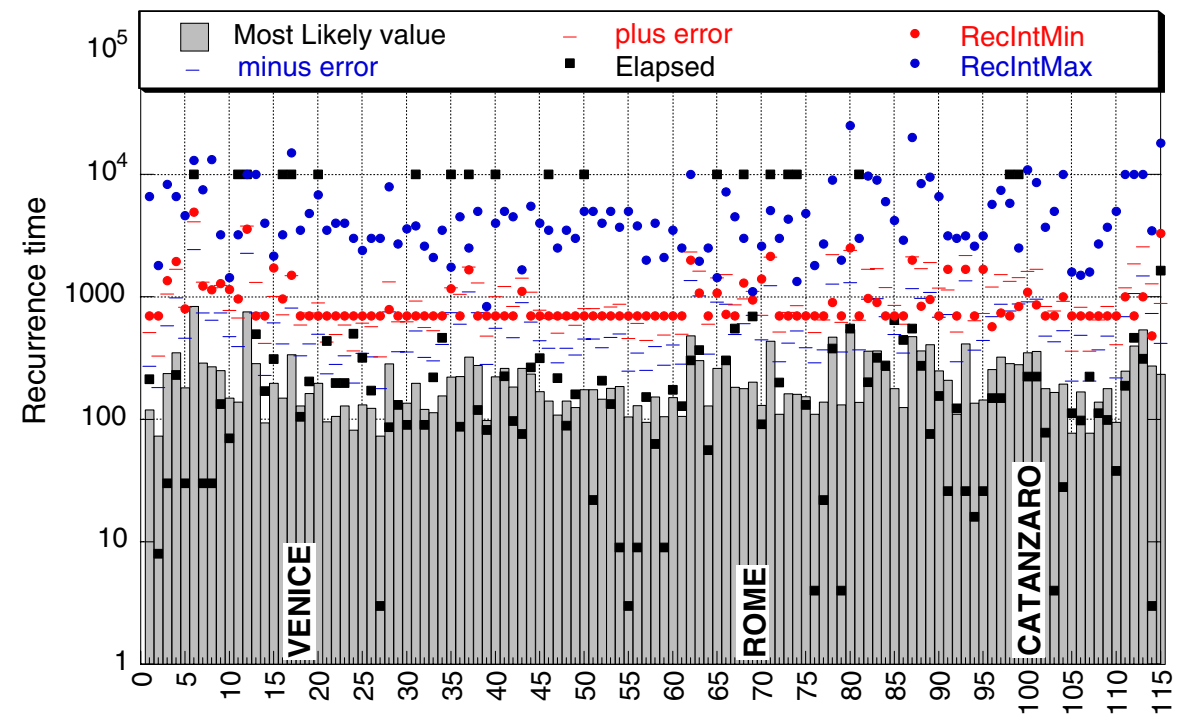

(error given by $\left.\sigma_{M}=0.1\right)^{2}$; (iv) magnitude computed as in (iii), but using the modified subsurface length ( $L \%)$ obtained by empirical regressions on aspect ratio (Peruzza and Pace 2002), if $L \%$ is smaller than the one given by DISS' compilers $\left(\sigma_{M}=0.25\right)$; (v) magnitude given by the DISS' compilers (MaxMag, $\sigma_{M}=0.1$ ). The five pairs of $T_{\text {ep }}$ and $\sigma_{T \text { ep }}$ have been finally combined to obtain the most likely value of recurrence time and relative error given by Anderson (1989):

$$
\begin{aligned}
& T_{\mathrm{ep}}^{(M L)}=\frac{\frac{T_{\mathrm{i}}}{\sigma_{\mathrm{i}}^{2}}+\frac{T_{\mathrm{ii}}}{\sigma_{\mathrm{ii}}^{2}}+\ldots+\frac{T_{\mathrm{v}}}{\sigma_{\mathrm{v}}^{2}}}{\frac{1}{\sigma_{\mathrm{i}}^{2}}+\frac{1}{\sigma_{\mathrm{ii}}^{2}}+\ldots+\frac{1}{\sigma_{\mathrm{v}}^{2}}} ; \\
& \sigma_{\mathrm{ep}}^{(M L)}=\sqrt{\frac{1}{\frac{\frac{1}{\sigma_{\mathrm{i}}^{2}}+\frac{1}{\sigma_{\mathrm{ii}}^{2}}+\ldots+\frac{1}{\sigma_{\mathrm{v}}^{2}}}{2}}} .
\end{aligned}
$$

This technique, which may be subjected to revision and implementation according to further choices adopted to perform propagation of errors, is correct if we accept the assumption of having small errors associated to the independent variables; it formally represents the dispersion derived from the use of different relationships, as the intrinsic errors of empirical regression relationships are taken into account. This kind of elaboration

\footnotetext{
${ }^{2}$ This value accounts for a variation, in a factor of 2 , of one of the constant values (strain drop or shear modulus) that enter into the $M_{3}$ formula.
}

is flexible and can be modified according to the confidence we attribute to the incoming data.

The result in terms of recurrence time and errors (hereinafter referred to as summer 2007 results), for the fault model DISS 3.02, is given in Fig. 8 . The mean recurrence times are very similar to the spring 2007 results, which consider only the variability in magnitude (comparison for selected sources in Fig. 9), and the differences pertain to some sources with peculiar geometrical characteristics of the fault rupture. The coefficient of variation is not as scattered as it was in Fig. 7b, and it is still compatible with a time-dependent approach; $\alpha$ 's given by formal error propagation all lie in a narrow range, from 0.22 to 0.36 . It is interesting to note that this interval corresponds to the peak in $\alpha$ distribution obtained by Mucciarelli with trial sampling on the longest earthquake sequence available in Italy (Fucino Fault with five events, Mucciarelli 2007). It is worth mentioning that the uncertainties associated to the GG sources (and then $\alpha$ 's) are widely compatible with nonPoissonian models, and they reflect the choices made in designing the fault reference model of DISS (characteristic earthquake hypothesis). If we accept that aperiodicity parameter obtained for an observed set of interoccurrence times hosts an epistemic and an aleatory component, the $\alpha$ values here computed account only for the first term. They, therefore, represent a lower bound to 

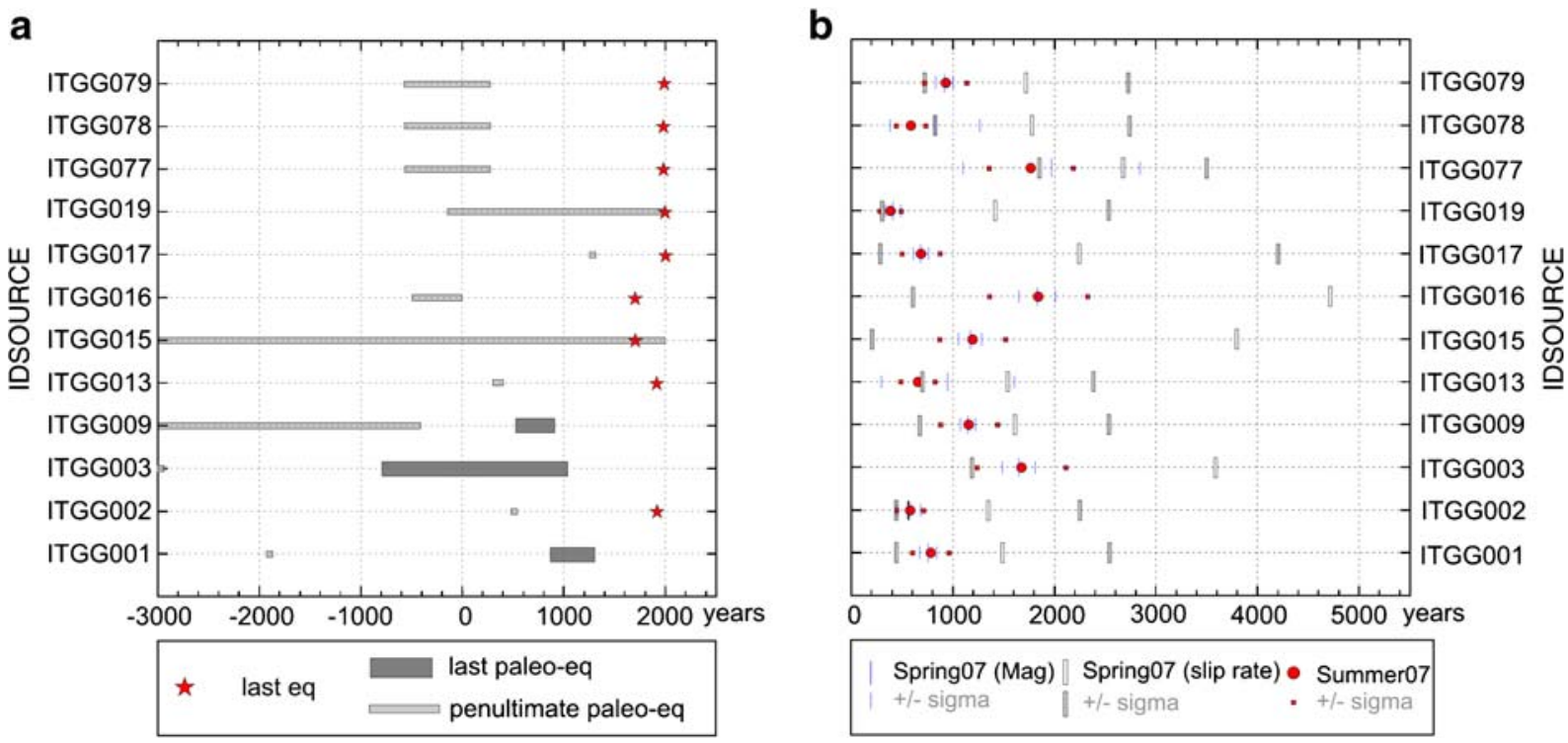

Fig. 9 Comparison of observed and computed interevent times for DISS 3.02 GG sources: a date of the characteristic earthquakes associated to the faults; b recurrence intervals computed for the same sources. Explanations are given in the text

the periodicity character that could be assigned to the sources. To account for an unknown aleatory component in the process, the final computation in terms of probabilities done using these values will be compared with preset values $(\alpha=0.5,0.7)$.

\subsubsection{Validation}

An effective validation of indirect, theoretical recurrence time with observations is not feasible right now; moreover, if we consider the average slip rate of Italian faults and the time/money resources actually invested for trenching, it is reasonable to assume that it will not be feasible in the next decades too. The simulation of synthetic sequences of earthquakes on a fault (e.g., Mucciarelli 2007; Parsons 2005) should be an effective tool for exploiting the distribution in time and size of events, but nevertheless it could be applied only to a small subset of faults.

In Fig. 9, we show a visual comparison between the observed interevent times (left frame) and the calculated ones (symbols in the frame on the right). Only for 12 faults reported in the DISS database (about 10\%) we know the occurrence of at least two large events (one interevent time); excluding the last event, most of the dates are wide or open intervals derived from paleoseismic records. The calculated recurrence interval is usually shorter than the graphed interevent time, but large uncertainties affect the paleoseismic events dating. In several other cases, we do have historical and/or instrumental earthquakes that can be associated to the activity of individual sources, but with relatively small magnitudes not comparable to the maximum expected ones and, therefore, not useful to constrain recurrence parameters in a full characteristic earthquake model hypothesis.

We did some tests to check the consistency of the magnitude and recurrence time obtained in our computation by seismic moment budgeting on the historical earthquake catalog (CPTI Working Group 2004). The detailed description of these tests is out of the scope of this paper, and therefore, we present here only simplified graphs and considerations. We compared the total seismic moment release and seismic moment rate according to two working hypothesis.

The first is a subdivision of the Italian territory on the basis of known and widely accepted zoning in seismotectonic districts or domains, which can be considered homogeneous in terms of kinematics and active tectonics with the bound- 
aries that are defined using the major active structural elements, together with seismological (e.g., earthquake focal mechanisms), rheologic, and geodetic data. Starting from several papers in literature (e.g., Lavecchia et al. 2007a, b; Oldow and Ferranti 2006; see also the documentation of Seismic Zonation ZS9 at http://ibogfs.df.unibo.it/ user2/paolo/www/ATLAS/ZS9/ZS9.html), we defined eight domains, mapped in Fig. 10a together with the DISS 3.02 individual sources. We computed for each domain the total seismic moment budget, from earthquakes in the catalog, and characteristic magnitudes of GG sources. By using a simplified assumption of completeness of the catalog in the last four centuries, we derived also the seismic moment rate for each district. Similarly, by using for the individual sources the magnitude and recurrence intervals obtained in the previous paragraphs, we computed seismic moment rates pertaining to the GG sources in the districts. The results are reported in Table 2. Note that the total seismic moment released by the individual sources is comparable (in a factor of 10) with the budget obtained from the historical catalog; exceptions are those districts with obvious difficulties in parameterizing geological individual sources (Tyrrhenian extensional domain (e) or Southern compression (h)) and the CentralEastern Alps (b) with a surplus of moment release due to GG sources only. If the moment rate is considered, the budgeting of historical catalog and individual sources is biased by the adopted completeness assumptions.

The second approach focuses on plate boundary only. Three lines have been schematically drawn in Fig. 10b, representing the seismic belt corresponding to the Europe-Africa indentation: a hypothetical line crosses the Southern Adriatic sea to represent the interpretations of Adria plate's fragmentation (see Meletti et al. 2000; Oldow et al. 2002 and references therein). By considering that the seismicity along the belt is the complex response to differential deformation velocities, we graphed the cumulative seismic a

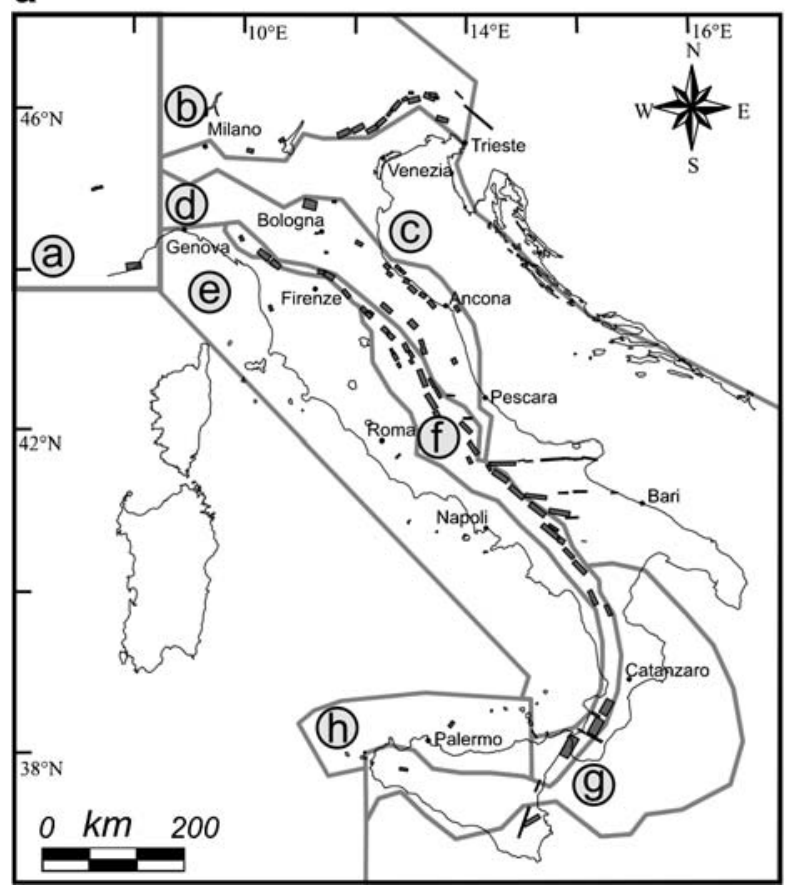

Fig. 10 Map view of the test done on seismic moment budget: a DISS 3.02 GG sources (gray rectangles) and geodynamic domains (gray polygons with corresponding let- b

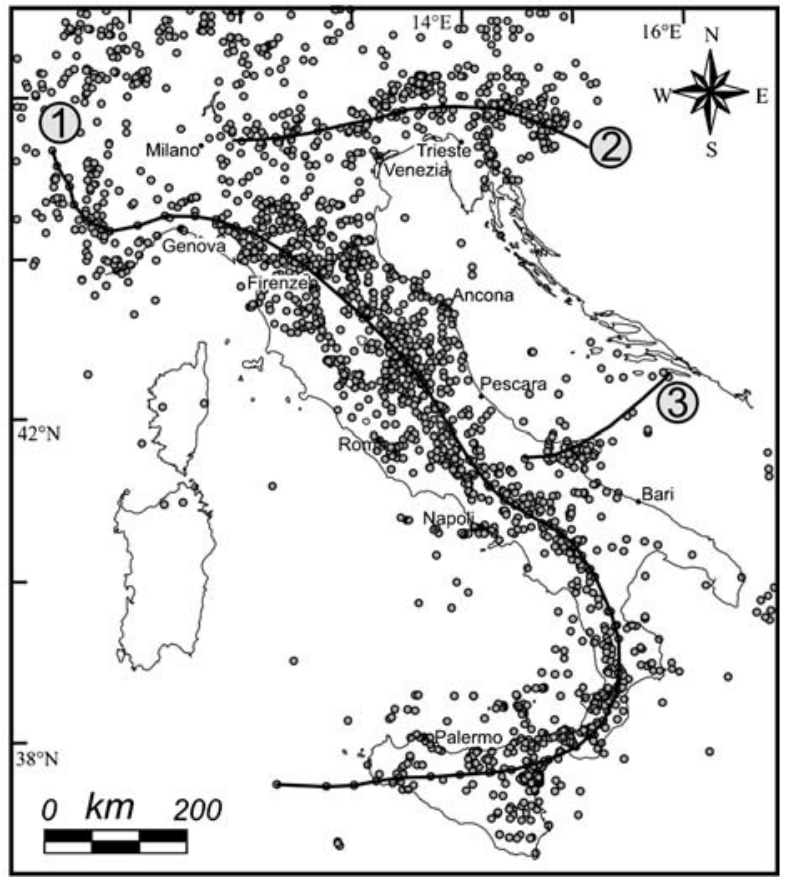

ters); b location of $M \gtrsim 5.5$ earthquakes in CPTI04 catalog (CPTI Working Group 2004) and schematic representation of plate boundaries. See text and Table 2 
Table 2 Seismotectonic domains (letters, see Fig. 10a) and simplified plate boundaries (numbers, see Fig. 10b): surface and total length is given in column 2; columns 3 to 5 show the total seismic moment (given in newton meter) released by the catalog and by the GG sources (with uncertainties); columns 6 to 8 show the total moment rate obtained by extrapolation of the earthquake catalog seismicity in the last four centuries or by the magnitude/recurrence time parameters of individual sources

\begin{tabular}{lrllllll}
\hline Domain/boundary & $\begin{array}{c}S\left(\mathrm{~km}^{2}\right) / \\
L(\mathrm{~km})\end{array}$ & $\begin{array}{l}\text { Cum } M_{0} \\
\text { CPTI04 }\end{array}$ & $\begin{array}{l}\text { Cum } M_{0} \\
\mathrm{GG} 3.02\end{array}$ & $\begin{array}{l}\text { Cum } M_{0} \\
\mathrm{GG} \pm \sigma_{M}\end{array}$ & $\begin{array}{l}M_{0} \text { rate } \\
\text { CPTI04 }\end{array}$ & $\begin{array}{l}M_{0} \text { rate } \\
\mathrm{GG} 3.02\end{array}$ & $\begin{array}{l}M_{0} \text { rate } \\
\mathrm{GG} \pm \sigma_{M}\end{array}$ \\
\hline $\mathrm{a}$ & 72,619 & $1.7 \mathrm{E}+19$ & $3.8 \mathrm{E}+18$ & $1.9 / 7.7 \mathrm{E}+18$ & $4.0 \mathrm{E}+16$ & $4.7 \mathrm{E}+15$ & $3.2 / 7.4 \mathrm{E}+15$ \\
$\mathrm{~b}$ & 66,677 & $5.2 \mathrm{E}+19$ & $\mathbf{7 . 6 E}+\mathbf{1 9}$ & $3.8 / 15 \mathrm{E}+19$ & $6.0 \mathrm{E}+16$ & $\mathbf{8 . 4 E}+\mathbf{1 6}$ & $\mathbf{5 . 8} / \mathbf{1 3 E}+\mathbf{1 6}$ \\
$\mathrm{c}$ & 296,110 & $2.5 \mathrm{E}+20$ & $1.3 \mathrm{E}+20$ & $6.8 / 27 \mathrm{E}+19$ & $5.0 \mathrm{E}+17$ & $1.9 \mathrm{E}+16$ & $6.5 / 15 \mathrm{E}+16$ \\
$\mathrm{~d}$ & 44,178 & $3.5 \mathrm{E}+19$ & $1.6 \mathrm{E}+19$ & $7.9 / 31 \mathrm{E}+18$ & $6.0 \mathrm{E}+16$ & $2.3 \mathrm{E}+16$ & $1.6 / 3.5 \mathrm{E}+16$ \\
$\mathrm{f}$ & 120,178 & $5.6 \mathrm{E}+20$ & $1.9 \mathrm{E}+20$ & $9.4 / 38 \mathrm{E}+19$ & $1.0 \mathrm{E}+18$ & $2.1 \mathrm{E}+17$ & $1.4 / 3.3 \mathrm{E}+17$ \\
e & 36,883 & $3.4 \mathrm{E}+19$ & $9.6 \mathrm{E}+17$ & $4.8 / 19 \mathrm{E}+17$ & $3.0 \mathrm{E}+16$ & $2.3 \mathrm{E}+15$ & $1.6 / 3.5 \mathrm{E}+15$ \\
g & 75,490 & $6.5 \mathrm{E}+19$ & $2.5 \mathrm{E}+18$ & $1.3 / 5.0 \mathrm{E}+18$ & $1.0 \mathrm{E}+17$ & $3.3 \mathrm{E}+15$ & $2.3 / 5.1 \mathrm{E}+15$ \\
h & 29,450 & $7.2 \mathrm{E}+18$ & $2.4 \mathrm{E}+18$ & $1.2 / 4.7 \mathrm{E}+18$ & $1.0 \mathrm{E}+16$ & $3.5 \mathrm{E}+15$ & $2.4 / 5.5 \mathrm{E}+15$ \\
1 & 1,730 & $9.0 \mathrm{E}+20$ & $2.4 \mathrm{E}+20$ & $1.2 / 4.7 \mathrm{E}+20$ & & \\
2 & 510 & $6.9 \mathrm{E}+19$ & $\mathbf{7 . 6 E}+\mathbf{1 9}$ & $3.8 / 15 \mathrm{E}+19$ & & \\
3 & 239 & $2.4 \mathrm{E}+19$ & $\mathbf{1 . 1 E}+\mathbf{2 0}$ & $5.4 / 21 \mathrm{E}+19$ & & \\
\hline
\end{tabular}

In bold are the domains/boundaries with an excess of energy release $\left(M_{0}(\mathrm{GG}\right.$ sources $\left.)>M_{0}(\mathrm{catalog})\right)$

moment along the line, using the progressive distance from one line's end. Earthquakes and or individual sources inside an $80-\mathrm{km}$ wide buffer are projected onto the line using their minimum distance from the line. Resulting trends are graphed in Fig. 11, and the total budget is reported in Table 2 too. Note the excess of seismic moment budget now for the two W-E oriented lines, while the total seismic moment along the "main" plate margin is reasonably preserved. The slope changes in the graphs of cumulative seismic moment versus distance (enhanced in Fig. 11 with colored trait segments) account for a progressive increase of deformation from North to South, in agreement with the geodynamic interpretations. Note the similar shape of cumulative seismic moment for line 1 derived from the catalog (Fig. 11a) and from the GG sources (gray dots in Fig. 11d). Further considerations are out of the scope of this paper, but we believe that additional investigations on similar moment budgeting may provide useful feedback for the identification and parameterization of individual sources.

\subsection{Elapsed time}

The last ingredient necessary to test the timedependent probability of a characteristic earthquake occurrence is the time elapsed since the last event. The DISS database reports for each individual geological source the elapsed time since the last large event (from 2,000 B.C.), except for 16 sources that do not have an associated earthquake; a fictitious elapsed time equal to 9,999 is assigned to these sources and to four other sources having large uncertainties in dating the events (last event recognized in paleoseismic trenches and studies only). We entered real and fictitious elapsed times into the time-dependent computations, but only a Poisson approach is reasonable if the date of the last event is lacking.

\section{Results}

The combination, in the BPT renewal model, of recurrence time, $\alpha$ value, and time elapsed since the last event gives the conditional earthquake probability of having a characteristic earthquake in the next $t$ years:

$$
\begin{gathered}
P\left(T_{\text {elap }} \leq T \leq T_{\text {elap }}+\Delta T \mid T>T_{\text {elap }}\right) \\
=\frac{P\left(T_{\text {elap }} \leq T \leq T_{\text {elap }}+\Delta T\right)}{1-P\left(0 \leq T \leq T_{\text {elap }}\right)} .
\end{gathered}
$$

A short description of the earthquake probability computations released from 2004 to 2007 

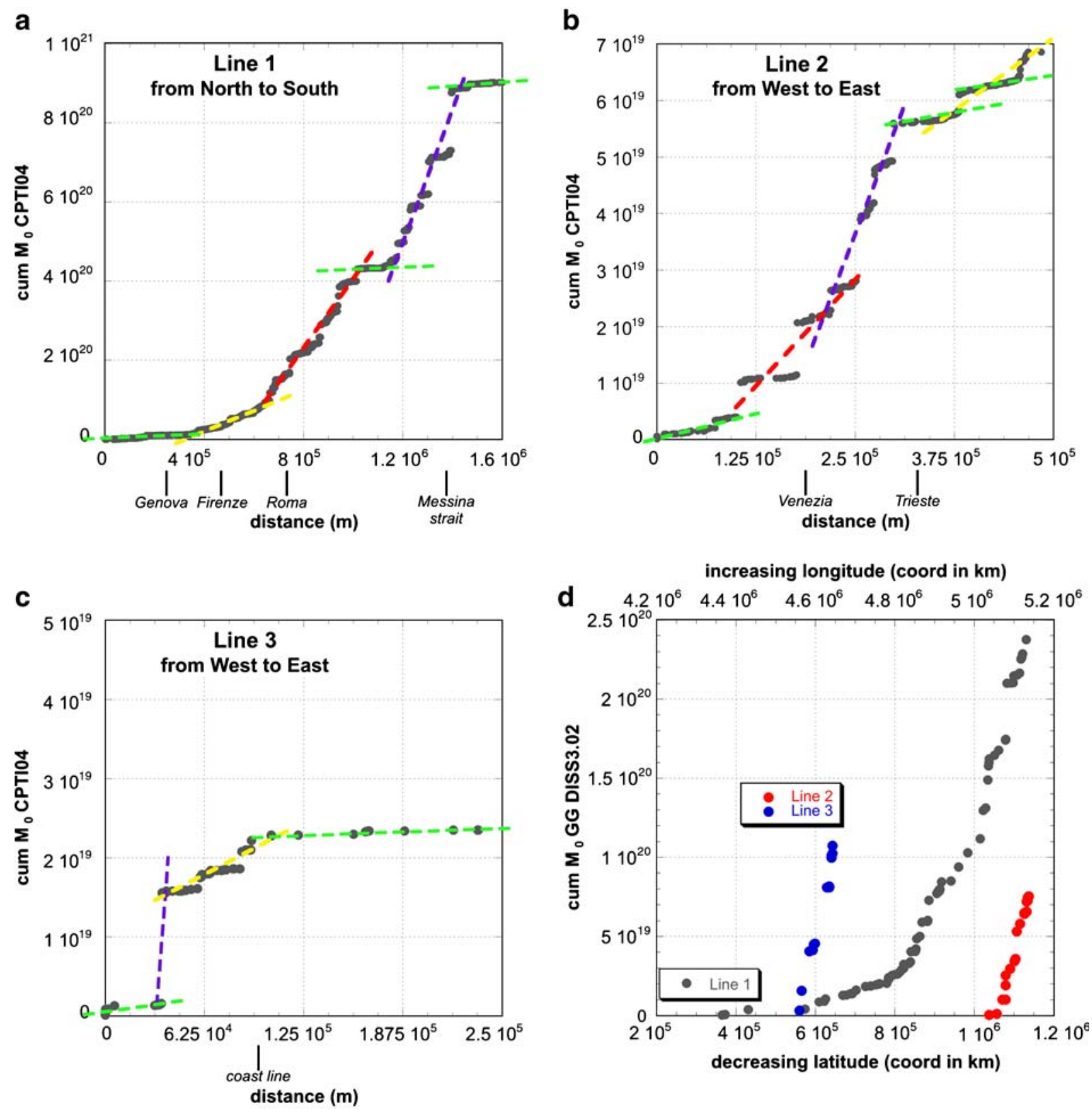

Fig. 11 Cumulative seismic moment graphs versus distance: a earthquakes in CPTI04 catalog (CPTI Working Group 2004) inside the $80-\mathrm{km}$ distance from line 1 in Fig. 10; b the same with line 2; c the same with line 3;

is given to represent the conceptual evolution in data treatment, and changes in the fault model too (from DISS 2.05 to 3.02). Results are summarized in Fig. 12, and additional maps/graphics are presented as Electronic Supplementary Materials.

d characteristic earthquake of DISS 3.02 along the three lines, distance given according to decreasing latitude for line 1 and to increasing longitudes for lines 2 and $3 . M_{\mathrm{o}}$ given in newton meter. See text and Table 2

The first elaborations are dominated by the reference fault model and by the assumptions made for the sources lacking the date of the last event; the results released in 2004 (end of previous project Amato and Selvaggi 2004; Peruzza 2006a, 
using DISS 2.05, see also ESM 3) and in 2006 (first phase of S2 project, DISS 3.0, see ESM 4) are influenced by a fictitious elapsed time, a priori imposed to the fault. In 2006, the elapsed time has been fixed equal to the mean recurrence time, a choice made to enhance the conditional probability of having an event in the next 30 years, but that represents an artifact. If we compare the earthquake probabilities obtained using variable magnitude but a fixed mean value of slip rate (labeled with "mag" in the legend of Fig. 12, see ESM 4) or variable slip rate with fixed magnitude (labeled "slip"), we clearly recognize the effect of uncertainties on slip rate. In the latter case, very low values of probabilities are expected in the time period of interest, and the initial timedependent, characteristic earthquake assumptions are no more consistent with the high aperiodicity values obtained ( $\alpha$ tends to 1 ), which are compatible with Poisson more than quasiperiodic processes.

The spring 2007 results (Peruzza 2007) have been computed for internal use in the $\mathrm{S} 2$ project only. The probability of having a characteristic earthquake on DISS 3.02 GG sources in the next 30 years (since 2006) has been computed in a very similar way to the ones named "mag (2006)" in Fig. 12. The differences are due to: (a) the changes in parameters of GG sources given in DISS 3.02; (b) the choice of using a very long elapsed time (approximately 10,000 years, to avoid fake effects of periodicity) for those 20 sources not having the date of the last event (comments on numerical precision when dealing with the queue of BPT distribution hereinafter). The probabilities are mapped in ESM 5 using the time-dependent BPT distribution function and the exponential formulation of time-independent Poisson processes. Only five sources exhibit a significant conditional probability, higher than the one associated to traditional stationary application; from $\mathrm{N}$ to $\mathrm{S}$, they are: Ferrara (N. 20, ITGG090), Zola Pedrosa (N. 24, ITGG091), Ascoli Satriano (N. 85, ITGG082), Bisceglie (N. 86, ITGG083), and Aspromonte Nord (N. 105, ITGG040). The mean of the Poissonian probabilities in 30 years is approxi-

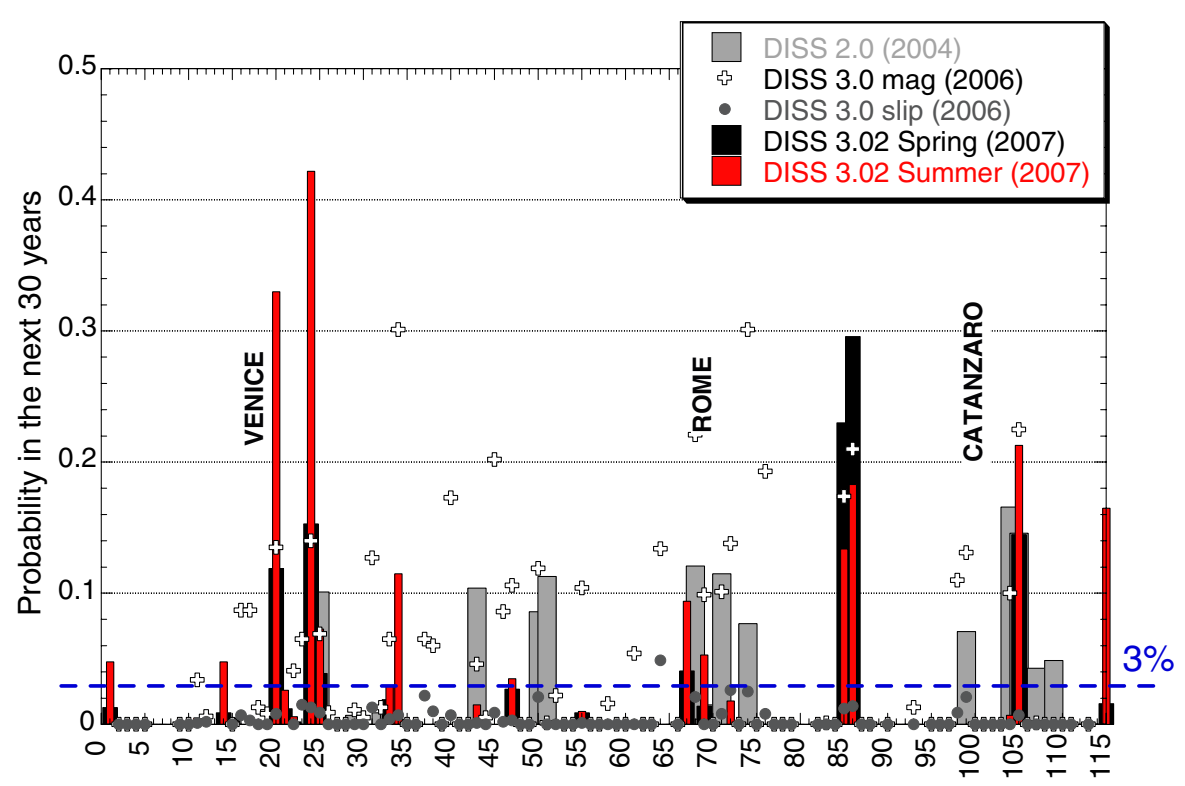

Fig. 12 Comparison of probability of having a characteristic earthquake conditional to the time elapsed since the last event. BPT renewal model is used with different fault model (in the legend, versions of DISS, the year refers to the date of results' release) and different choices in computation (see the text). Forecasts refer to the next
30 years from 2003 using DISS 2.0, from 2006 using DISS 3.x. Sources are sorted according to decreasing latitude and increasing longitude (source number in the full list of ESM 1). The dashed blue line shows the threshold of $3 \%$ of having a characteristic earthquake, adopted in Japan to define highly probable sources in a 30 -year perspective 


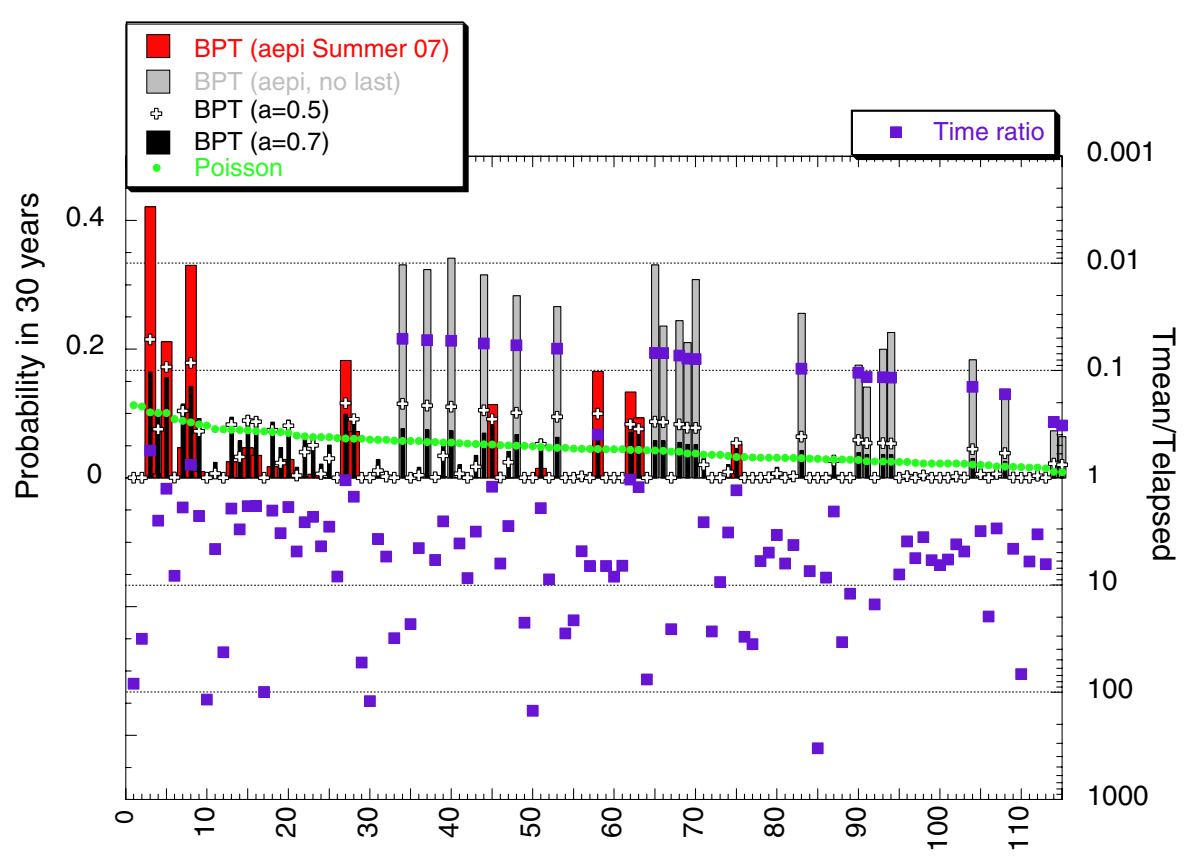

Fig. 13 Final results: probability of having a characteristic earthquake on DISS 3.02 GG sources. BPT renewal model with different $\alpha$ values and Poisson model; BPT model applied to all the sources with implementation of numerical precision in the calculus. The sources lacking the date of the last event using fictitious elapsed time of 9,999 years are easy to reckon (gray bars of "summer 2007, no last" in the legend, small time ratios). Sources sorted according to decreasing Poisson probability: all numerical values and the source number are reported in ESM 7 mately $4 \%$. Accepting the definition of "highly probable sources" given in Japan (probabilities higher than $3 \%$ in 30 years, values defined by Shimazaki 2006), about three fourths of the GG sources, if represented by a Poisson process, should, therefore, be taken as highly probable earthquakes.

The tests done during the first year of the project suggested to use geodetic observations to reduce the uncertainties on slip rates of the faults, but the results obtained are hardly credible and do not reach significant improvements. For these reasons, the final earthquake probabilities do not introduce geodetic constraints, but formal analysis of error propagation in the computation of statistical proxies for recurrence interval and its variability, and use also some preset aperiodicity values.

The results named summer 2007 are the ones obtained via error propagation (see Fig. 12, map in ESM 6, table in ESM 7 as well). These results are in good qualitative agreement with those labeled spring 2007. In particular, using a BPT renewal model, one obtains in both cases the same set of the most "prone" seismic sources, although differently sorted with respect to probability. This is an effect due to the more stable values obtained for the aperiodicity factor by Eq. $11 ; \alpha_{\text {epi }}$ ranges in the interval 0.22-0.36, depicting quasiperiodic behavior. The 20 sources (mapped in black in ESM 6) still lacking the date of the last event should be considered only under Poisson assumptions. The mean value of Poissonian probabilities in 30 years is approximately $5 \%$, somehow higher than spring 2007, as the mean recurrence times are slightly shorter (see statistics in Table 1).

Finally, to account for an unknown aleatory component in the periodicity character of the sources, we applied predefined $\alpha$ values (respectively of 0.5 and 0.7 ) to the same mean recurrence and elapsed times of summer 2007 dataset. By using sophisticated algorithms with symbolic 
algebra software, the computation of conditional probabilities has been performed with infinite precision, avoiding the numerical instabilities recognized when dealing with numerical integration of probability density function using standard Fortran routines on the queue of BPT distributions. The results were in agreement with the previous ones, for all but the sources having the very long, fictitious elapsed time of about 10,000 years. In these cases, instead of null probabilities previously computed, we obtained finite values that reflect the asymptotic behavior of BPT (values in gray-shaded cells in ESM 7). Probabilities of having a characteristic earthquake in the next 30 years (since 2006) using BPT renewal models $\left(\alpha_{\text {epi }}\right.$ and preset values) are graphed in Fig. 13 together with the probability of having at least one event in 30 years (green dots) according to a Poisson process. Sources are sorted by decreasing Poisson probabilities. The ratio of the mean recurrence over elapsed time is plotted too (right $y$-axis).

The sources with high probabilities of an impending earthquake (greater than $3 \%$ in the period 2007-2036) are mainly intermediate earthquake faults with characteristic $M<6$, having an elapsed time of 0.7-1.2 times the recurrence interval. Probability decreases if we move from quasiperiodic $\left(\alpha_{\text {epi }}\right)$ toward more stationary processes ( $\alpha=0.7$ ), if the time elapsed since the last event is equal or higher than the mean recurrence time; conversely, we note an increase of probability for sources having $T_{\text {elap }} \sim 30-50 \% T_{\text {mean }}$. When the time ratio is greater than 5 , we always obtain very low probability values. Given the DISS 3.02 reference fault model, the most "prone" sources are located in Northern Apennines, Abruzzo-Molise region and Apulia, and in the Calabrian arc. All the sources without the date of the last event, exhibit similar high probabilities, due to the asymptotic behavior of BPT, if we assign them very long elapsed times and perform the computation with adequate numerical precision.

As far as the development of the timedependent approach for Italy concerns, this analysis suggests that the highest priorities are the following. First, a more careful estimate of the date of the last event should be obtained for the some 20 sources still under scrutiny. Second, the applicability of the pure characteristic event model should be more deeply investigated on each source.

\section{Concluding remarks}

We present the elaborations done in the frame of the 2-year project "S2-Assessing the seismogenic potential and the probability of strong earthquakes in Italy" funded in 2005 by the DPC to the national seismological agency INGV. We compute the earthquake probabilities of occurrence for major, characteristic events on given individual sources all over the Italian territory, using the fault models released for the project's purposes (namely, the DISS), a BPT renewal model, and an ad hoc formal error propagation in estimating the mean recurrence intervals and variability of individual sources. Interevent times in Italy are absolutely insufficient to characterize the fault behavior. We derive mean recurrence time firstly by treating separately the uncertainties in slip rate assignment, and in the characteristic magnitude (Fig. 7). We demonstrate that a timedependent approach is effective only if we are able to constrain the large variability in slip rate or introduce formal error propagation. The constraints introduced in some tests by geodetic observations and modeling are by now not satisfactory (Fig. 6). We, therefore, formally propagate the errors of magnitude and slip rate, obtaining the most likely value of recurrence interval and error for each source (Fig. 8); these values are often shorter than the few interevent times available (Fig. 9), but in agreement with completeness considerations on the earthquake catalog and with observations of departures from pure characteristic model for some sources. A preliminary test done on seismic moment budgeting of GG sources and historical catalog (Figs. 10 and 11) gives some interesting elements to critically review the reference fault model in some areas. We compute finally the conditional probability of occurrence in the next 30 years (since 2006) with variable $\alpha$ 's derived from error propagation and fixed preset $\alpha$ 's as high as 0.5 and 0.7 (Fig. 13). We compare these results with the time-independent Poissonian prob- 
ability, whose mean value for $\mathrm{GG}$ sources in 30 years is approximately $5 \%$.

In a time-dependent perspective, i.e., when the date of the last event is known, only $10-15 \%$ of the 115 sources exhibit a probability of a characteristic earthquake in the next 30 years higher than the equivalent Poissonian probabilities: this percentage is weakly influenced by the aperiodicity coefficient given. If we accept the Japanese conventional choice of probability threshold greater than $3 \%$ in 30 years to define "highly probable sources," mainly intermediate earthquake faults with characteristic $M<6$, having an elapsed time of 0.7-1.2 times the recurrence interval are the most "prone" sources. The number of highly probable sources rises by increasing the aperiodicity coefficient (from 14 sources in the case of variable $\alpha$ ranging between 0.22 and 0.36 to 31 sources out of 115 in the case of an $\alpha$ value fixed at 0.7 ). On the other hand, in stationary time-independent approaches, more than two thirds of all sources are considered probabilistically prone to an impending earthquake.

The aperiodicity factor does influence the absolute values of probabilities, but not the relative ranking of sources if the elapsed time is equal or greater than the mean recurrence time. Relevant is the contribution of quasistationary model for sources with time ratios (mean recurrence over elapsed time) of $2-5$. Negligible is the timedependent probability of very recently activated sources. This is a result that should be taken into consideration in establishing seismic mitigation measures in Italy. The highest priority, in the development of the fault model, has to be given to the assignment of a date/interval for the last event to the 20 sources still lacking it and to a careful check on the applicability of pure characteristic model to Italian fault sources.

Acknowledgements We thank Francesco Visini and Monica Sugan for the GIS assistance. Two anonymous reviewers gave many suggestions and comments to improve the paper; we thank them for their clarity and conciseness. This research has been developed in the frame of the Project S2 - Assessing the seismogenic potential and the probability of strong earthquakes in Italy (Slejko and Valensise coord.) - S2 Project has benefited from funding provided by the Italian Presidenza del Consiglio dei Ministri - Dipartimento della Protezione Civile (DPC).
Sientific papers funded by DPC do not represent its official opinion and policies.

Open Access This article is distributed under the terms of the Creative Commons Attribution Noncommercial License which permits any noncommercial use, distribution, and reproduction in any medium, provided the original author(s) and source are credited.

\section{References}

Abaimov SG, Turcotte DL, Rundle JB (2007) Recurrencetime and frequency -slip statistics of slip events on the creeping section of the San Andreas fault in central California. Geophys J Int 170:1289-1299. doi:10.1111/j.1365-246X.2007.03479.x

Amato A, Selvaggi G (2004) Terremoti probabili in Italia tra l'anno 2000 e il 2030: elementi per la definizione di priorità degli interventi di riduzione del rischio sismico. In: GNDT (ed) Scientific reports-3rd year of activities. Rome, Italy. Available at http://gndt.ingv.it/ Att_scient/PE2002_Brief_Reports/brief_reports.htm

Anderson HL (ed) (1989) A physicist's desk reference. American Institute of Physics, New York

Capuano P, Zollo A, Emolo A, Marcucci S, Milana G (2000) Rupture mechanism and source parameters of Umbria-Marche mainshocks from strong motion data. J Seismol 4:463-478. doi:10.1023/A:1026523703464

Casarotti E, Piersanti A (2005) A synthetic fault system in a spherical and viscoelastic earth model. Geophys J Int 160:581-591. doi:10.1111/j.1365-246X.2005.02457.x

CPTI Working Group (2004) Catalogo Parametrico dei Terremoti Italiani, vers. 2004 (CPTI04). INGV, Bologna. Available at http://emidius.mi.ingv.it/CPTI/ home.html

Cramer CH, Petersen MD, Cao T, Toppozada TR, Reichle M (2000) A time-dependent probabilistic seismichazard model for California. Bull Seismol Soc Am 90:1-21. doi:10.1785/0119980087

DISS Working Group (2007) Database of Individual Seismogenic Sources (DISS), Version 3.0.4: a compilation of potential sources for earthquakes larger than $\mathrm{M}$ 5.5 in Italy and surrounding areas. In: INGV-Istituto Nazionale di Geofisica e Vulcanologia (ed). Available at http://www.ingv.it/DISS

Ellsworth WL, Matthews MV, Nadeau RM, Nishenko SP, Reasenberg PA, Simpson RW (1999) A physicallybased earthquake recurrence model for estimation of long-term earthquake probabilities. US Geol Surv Open-File Rept 99-522

Faenza L, Marzocchi W, Boschi E (2003) A nonparametric hazard model to characterize the spatio-temporal occurrence of large earthquakes; an application to the Italian catalogue. Geophys J Int 155:521-531. doi:10.1046/j.1365-246X.2003.02068.x 
Field EH, Johnson DD, Dolan JF (1999) A mutually consistent seismic-hazard source model for Southern California. Bull Seismol Soc Am 89:559-578

Field EH, Jordan TH, Cornell CA (2003) OpenSHA: a developing community-modeling environment for seismic hazard analysis. Seismol Res Lett 74:406-419

Gabrieli C, Braitenberg C, Nagy I, Zuliani D (2006) Tilting and horizontal movement at and across the northern border of the Adria plate. In: Sansò F, Gil AJ (eds) Geodetic deformation monitoring: from geophysical to engineering roles. Springer Berlin Heidelberg, pp 129-137

Gruppo di Lavoro (2004) Redazione della mappa di pericolosità sismica prevista dall'Ordinanza PCM 3274 del 30 marzo 2003. Rapporto conclusivo per il Dipartimento di Protezione Civile. INGV, Milan-Rome, p 65

Hanks TC, Kanamori H (1979) A moment magnitude scale. J Geophys Res 84:2348-2350. doi:10.1029/ JB084iB05p02348

Heaton TH (2007) Will performance-based earthquake engineering break the power law? Seismol Res Lett 78:183-185. doi:10.1785/gssrl.78.2.183

Jordan HJ, Field EH, Somerville P (2006) USC-SCEC/ CEA technical report \#1. Southern California Earthquake Center, Los Angeles, CA

Kagan YY, Jackson DD (1991) Seismic gap hypothesis: ten years after. J Geophys Res 96:21419-21431. doi:10.1029/91JB02210

Kagan YY, Jackson DD (1999) Worldwide doublets of large shallow earthquakes. Bull Seismol Soc Am 89:1147-1155

Lavecchia G, De Nardis R, Visini F, Ferrarini F, Barbano MS (2007a) Seismogenic evidence of ongoing compression in eastern-central Italy and mainland Sicily: a comparison. Boll Soc Geol Ital 126:209-222

Lavecchia G, De Nardis R, Visini F, Ferrarini F, Barbano MS (2007b) Active thrusting as a possible seismogenic source in Sicily (Southern Italy): some insights from integrated structural-kinematic and seismological data. Tectonophysics 445:145-167. doi:10.1016/j.tecto.2007.07.007

Marzocchi W, Selva J, Cinti FR, Montone P, Pierdominici S, Schivardi R et al (2006) On the recurrence of large earthquakes: some insights from a model based on a realistic interacting fault system. Fall meeting, S12A-05

Matthews MV, Ellsworth WL, Reasenberg PA (2002) A Brownian model for recurrent earthquakes. Bull Seismol Soc Am 92:2233-2250. doi:10.1785/0120010267

Meletti C, Patacca E, Scandone P (2000) Construction of a seismotectonic model; the case of Italy. In: G. Panza F, Radulian M, Trifu CI (eds) Seismic hazards of the Circum-Pannonian region. Birkhaeuser, Basel, Switzerland

Mucciarelli M (2007) A test for checking earthquake aperiodicity estimates from small samples. Nat Hazards Earth Syst Sci 7:399-404

Oldow J, Ferranti L (2006) Fragmentation of Adria and active decollement tectonics within the Southern Peri-Tyrrhenian orogen, Italy. In: Pinter N, Grenerczy
G, Weber J, Stein S, Medak D (eds) The Adria microplate: GPS geodesy, tectonics and hazards. Springer, The Netherlands, pp 269-286

Oldow JS, Ferranti L, Lewis DS, Campbell JK, D'Argenio B, Catalano R et al (2002) Active fragmentation of Adria, the north African promontory, central Mediterranean orogen. Geology 30:779-782. doi:10. 1130/0091-7613(2002)030<0779:AFOATN > 2.0.CO;2

Pace B, Peruzza L, Lavecchia G, Boncio P (2006) Layered seismogenic source model and probabilistic seismichazard analyses in Central Italy. Bull Seismol Soc Am 96:107-132. doi:10.1785/0120040231

Pantosti D, Pucci S, Palyvos N, DeMartini PN, D'Addezio G, Collins PEF, Zabci C (2008) Paleoearthquakes of the Duzce fault (North Anatolian Fault Zone): insights for large surface faulting earthquake recurrence. J Geophys Res 113. doi:10.1029/2006JB004679

Parsons T (2005) Significance of stress transfer in timedependent earthquake probability calculations. J Geophys Res 110:1-20

Perea H, Atakan K (2007) Influence of slow active faults in probabilistic seismic hazard assessment: the northwestern margin of the València trough. Nat Hazards 43:379-396. doi:10.1007/s11069-007-9135-0

Peruzza L (ed) (1999) Progetto MISHA. Metodi Innovativi per la Stima dell'Hazard-Applicazione all'Italia Centrale: Trieste, Studio Gamma, p 176

Peruzza L (2006a) Earthquake probabilities and probabilistic shaking in Italy in 50 years since 2003: trials and ideas for the 3rd generation of Italian seismic hazard maps. Boll Geofis Teor Appl 47:515-548

Peruzza L (2006b) Extended report of the researches developed by UR 4.8 during the first phase of the project S2-Valutazione del potenziale sismogenetico e probabilita' dei forti terremoti in Italia. OGS Open File Report 2006/33-OGA16RISK, OGS, Sgonico, Italy, p 25

Peruzza L (2007) Note descrittive sui tempi di ricorrenza e probabilità di terremoto caratteristico nei prossimi 30 anni (dal 2007) associata alle GGsources del DISS v. 3.0.2. OGS Open File Report 2007/33-OGA11RISK, OGS, Sgonico, Italy, p 14

Peruzza L, Pace B (2002) Sensitivity analysis for seismic source characteristics to probabilistic seismic hazard assessment in Central Apennines (Abruzzo area). Boll Geofis Teor Appl 43:79-100

Peruzza L, Pace B, Lavecchia G, Boncio P (2007) Reply to "Comment on 'Layered Seismogenic Source Model and Probabilistic Seismic-Hazard Analyses in Central Italy' by B. Pace, L. Peruzza, G. Lavecchia, and P. Boncio" by W. Marzocchi. Bull Seismol Soc Am 97:1766-1768. doi:10.1785/0120070043

Petersen MD, Cao T, Campbell KW, Frankel AD (2007) Time-independent and time-dependent seismic hazard assessment for the state of California: uniform California earthquake rupture forecast model 1.0. Seismol Res Lett 78:99. doi:10.1785/gssrl.78.1.99

Scholz CH, Cowie PA (1990) Determination of the total strain from faulting using slip measurements. Nature 346:837-839. doi:10.1038/346837a0 
Schwartz DP, Coppersmith KJ (1984) Fault behavior and characteristic earthquakes; examples from the Wasatch and San Andreas fault zones. J Geophys Res 89:5681-5698

Selvaggi G (1998) Spatial distribution of horizontal seismic strain in the Apennines from historical earthquakes. Ann Geofis 41:241-251

Serpelloni E, Anzidei M, Baldi P, Casula G, Galvani A (2005) Crustal velocity and strain-rate fields in Italy and surrounding regions: new results from the analysis of permanent and non-permanent GPS networks. Geophys J Int 161:861-880. doi:10.1111/j.1365-246X. 2005.02618.x

Shimazaki K (2006) Long-term earthquake forecasts of Japanese earthquakes. Earthquake and shaking probabilities: helping society to make the right choice. EMCSC, Erice, Sicily

Slejko D, Valensise G (2006) Progetto S2-Valutazione del potenziale sismogenetico e probabilità dei forti terremoti in Italia. In INGV (ed). Available at
http://legacy.ingv.it/progettiSV/Progetti/Sismologici/ Relazioni_I_fase/

Slejko D, Valensise G (2007) Progetto S2-Valutazione del potenziale sismogenetico e probabilità dei forti terremoti in Italia. In: INGV (ed). Available at http:// legacy.ingv.it/progettiSV/Progetti/Sismologici/S2/

Stirling MW, Slejko D, Peruzza L, Pace B (2007) Seismotectonic modelling in Northeastern Italy. In: Science $\mathrm{G}$ (ed) Consultancy report, Trieste, Wellington, GNS, p 22

Valensise G, Pantosti D (eds) (2001) Database of potential sources for earthquakes larger than M 5.5 in Italy: Annali di Geofisica, v. 44 Rome, INGV, 180 p

Wells DL, Coppersmith KJ (1994) New empirical relationships among magnitude, rupture length, rupture width, rupture area, and surface displacement. Bull Seismol Soc Am 84:974-1002

Zoller G, Ben-Zion Y, Holschneider M, Hainzl S (2007) Estimating recurrence times and seismic hazard of large earthquakes on an individual fault. Geophys J Int 170:1300-1310. doi:10.1111/j.1365-246X.2007.03480.x 